\title{
A DFT/B3LYP study of the mechanisms of the $\mathrm{O}_{2}$ formation reaction catalyzed by the [(terpy) $\left(\mathrm{H}_{2} \mathrm{O}\right) \mathrm{Mn}^{\mathrm{III}}(\mathrm{O})_{2} \mathrm{Mn}^{\mathrm{IV}}\left(\mathrm{OH}_{2}\right)$ (terpy) $]\left(\mathrm{NO}_{3}\right)_{3}$ complex: A paradigm for photosystem II
}

\author{
Eduardo M. Sproviero \\ Department of Chemistry and Biochemistry, University of the Sciences, Philadelphia, Pennsylvania, 19104, United States
}

A R T I C L E I N F O

\section{Article history:}

Received 13 October 2016

Received in revised form 28 January 2017

Accepted 17 February 2017

Available online 20 February 2017

\begin{abstract}
A B S T R A C T
We present a theoretical study of the reaction pathway for dioxygen molecular formation catalyzed by the $\left[(\right.$ terpy $)\left(\mathrm{H}_{2} \mathrm{O}\right) \mathrm{Mn}^{\mathrm{III}}(\mathrm{O})_{2} \mathrm{Mn}^{\mathrm{IV}}\left(\mathrm{OH}_{2}\right)$ (terpy) $]\left(\mathrm{NO}_{3}\right)_{3}$ (terpy $=2,2^{\prime}: 6^{\prime}, 2^{\prime \prime}$-terpyridine) complex based on DFT-B3LYP calculations. In the initial state of the reaction, a partial oxido radical ( 0.44 spins) is formed ligated to $\mathrm{Mn}$. This radical is involved in a nucleophylic attack by bulk water in the $\mathrm{O}-\mathrm{O}$ bond reaction formation step, in which the oxido fractional unpaired electron is delocalized toward the outermost Mn of the $\mu$-oxo bridge, instead of the ligated Mn center. The reaction then follows with a series of proton-coupled electron transfer steps, in which the oxidation state, as well as the bond strength of the $\mathrm{OO}$ moiety increase, while the $\mathrm{OO}-\mathrm{Mn}(1)$ bond gets weaker until $\mathrm{O}_{2}$ is released. In this model, basic acetate ions from the buffer solution capture protons in the proton-transfer steps. In each step there is reduction of the $00-\mathrm{Mn}(1)$ binding strength, with concomitant increase of the $\mathrm{O}-\mathrm{O}$ bond strength, which culminates with the release of $\mathrm{O}_{2}$ in the last step. This last step is entropy driven, while formation of hydroperoxide and superoxide moieties is enthalpy driven. According with experiments, the rate-limiting step is the double oxidation of $\mathrm{Mn}(\mathrm{IV}, \mathrm{III})$ or peroxymonosulfate binding, which occur prior to the $\mathrm{O}-\mathrm{O}$ bond formation step. This supports our findings that the barriers of all intermediate steps are below the experimental barrier of $19-21 \mathrm{kcal} / \mathrm{mol}$. The implications of these findings for understanding photosynthetic water-splitting catalysis are also discussed.
\end{abstract}

(c) 2017 Elsevier Inc. All rights reserved.

\section{Introduction}

The oxygen-evolving complex (OEC) of photosystem II (PSII), is a $\mathrm{Mn}_{4} \mathrm{Ca}$ cofactor that catalyzes the oxidation of water to dioxygen in the thylakoid membrane of green plant chloroplasts and internal membranes of cyanobacteria, during the light period of photosynthesis [1,2]. Besides its biological significance, the OEC is a paradigm system for engineering direct solar fuel production catalysts since it is based on inexpensive metals and achieves an overall catalytic efficiency of water splitting that is yet to be matched by artificial systems [3]. Elucidating the mechanisms of the $\mathrm{O}-\mathrm{O}$ bond reaction formation is, therefore, central for understanding the catalytic mechanism of photosynthetic water oxidation as well as for the development of biomimetic catalysts for oxidation chemistry.

Bioinorganic model chemistry has provided important insights into the mechanism of photosynthetic water oxidation, in particular by inspiring the idea of a $\mathrm{Mn}-\mathrm{O}$ species as a key intermediate in the $\mathrm{O}-\mathrm{O}$ bond formation, created by the abstraction of $\mathrm{H}$-atoms from a water ligated to manganese [4-6].

Although many complexes have been considered as structural models for the OEC [7-16], only a few act also as functional models [17-26].

\footnotetext{
E-mail address: e.sproviero@usciences.edu.
}

Barely four classes of metal complexes are known to catalyze homogeneous water oxidation. These involve Ru dimmers [19,27-30], Mnbound porphyrin dimmers [18,21,31], a carboxylate-bridged MnII/II 2 dimer [23], and a complex containing a $\mathrm{Mn}-(\mu-\mathrm{O})_{2}-\mathrm{Mn}$ moiety [6].

Among these complexes, only the latter show clear structural resemblances with the actual OEC. Extended X-ray absorption fine structure (EXAFS) studies of PS II samples at the Mn K-edge reveal at least two 2.7- $\AA \mathrm{Mn}-\mathrm{Mn}$ backscattering distances that are characteristic of $\mathrm{Mn}-(\mu-\mathrm{O})_{2}-\mathrm{Mn}$ moieties [32-35]. The recent $1.95-$ and $1.9-\AA-$ resolution [36,37] X-ray crystal structures of the PS II, isotropic [38,39] and polarized [40,41] EXAFS [42], as well as DFT-B3LYP [43-45], and Quantum Mechanics/Molecular Mechanics (QM/MM) studies [46] revealed that the $\mathrm{Mn}$ atoms in the OEC are also linked via $\mu-\mathrm{O}$ bridges. Due to the structural and functional similarities the manganese complex [(terpy) $\left(\mathrm{H}_{2} \mathrm{O}\right) \mathrm{Mn}^{\mathrm{III}}(\mathrm{O})_{2} \mathrm{Mn}^{\mathrm{IV}}\left(\mathrm{OH}_{2}\right)$ (terpy) $]\left(\mathrm{NO}_{3}\right)_{3}$ (terpy $=2,2^{\prime}: 6^{\prime}, 2^{\prime \prime}-$ terpyridine) $[5,6,47](\mathbf{1})$, the "terpy" complex (Fig. 1), has been considered to be the only functional model of the OEC $[5,6,48]$.

The biomimetic complex 1 evolves $\mathrm{O}_{2}$ in aqueous solution, using only oxygen transfer oxidants, such as $\mathrm{NaClO}$, or $\mathrm{KHSO}_{5}$ (potassium peroxymonosulfate or oxone). While some authors advocate wateroxidation [5,6,49,50], others have debated about the source of oxygen evolution [22,51]. Using isotope labels, Brudvig et al. conducted an investigation of the identity of the reactant species involved in the oxygen 


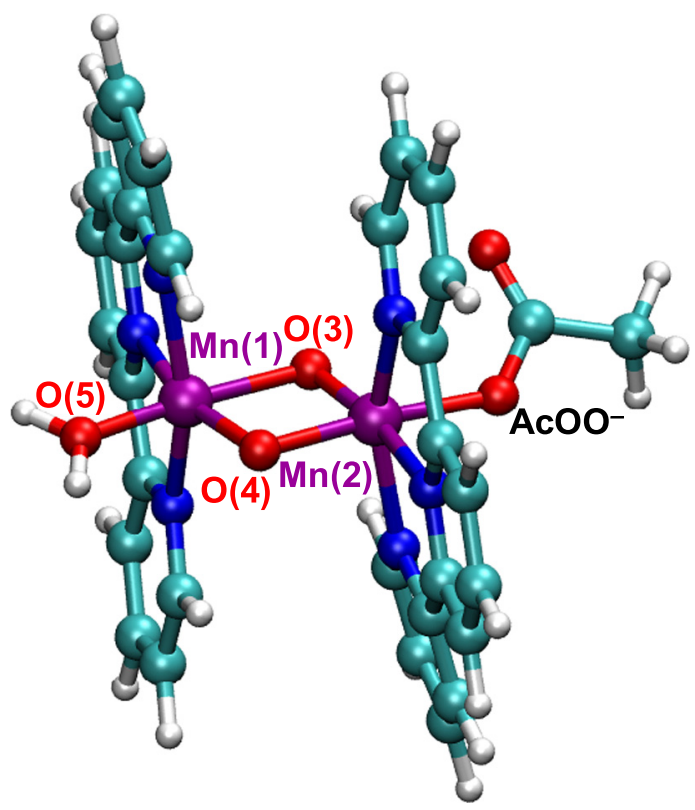

Fig. 1. The "terpy" complex 1: [(terpy) $\left(\mathrm{H}_{2} \mathrm{O}\right) \mathrm{Mn}^{\mathrm{III}}(\mu-\mathrm{O})_{2} \mathrm{Mn}^{\mathrm{IV}}\left(\mathrm{CH}_{3} \mathrm{CO}_{2}\right)($ terpy $\left.)\right]\left(\mathrm{NO}_{3}\right)_{3}$ (terpy $=2,2^{\prime}: 6^{\prime}, 2^{\prime \prime}$-terpyridine).

evolution reaction catalyzed by the terpy complex [6]. One of the reactants for the $\mathrm{O}-\mathrm{O}$ formation reaction is the terpy complex in a high spin $\mathrm{Mn}^{\mathrm{V}}(1)-\mathrm{Mn}^{\mathrm{IV}}(2)$ state. For the other reactant, several species involved were identified, including two oxygen atoms from bulk water, one oxygen atom from water and the second from oxone, or both oxygen atoms from oxone. This observation alone does not prove the atoms of $\mathrm{O}_{2}$ can come solely from water, as $\mathrm{O}$ atoms of water may exchange with other oxygen-containing species in the system. Therefore, it was additionally established that in systems using oxone as oxidant, water does not undergo $\mathrm{O}$ atom exchange with the oxidant $\mathrm{HSO}_{5}^{-}$, the $\mathrm{SO}_{4}^{2-}$ ions present alongside with $\mathrm{HSO}_{5}^{-}$, or with the $\mathrm{NO}_{3}^{-}$counterions of 1 [48].

A common way to avoid the use of oxygen transfer oxidants is using the $\mathrm{Ce}^{\mathrm{IV}}$ oxidant. It has been shown that $\mathbf{1}$ catalyze the oxidation of water with the $\mathrm{Ce}^{\mathrm{IV}}$ oxidant, if attached to kaolin clay $[22,52]$. In a further work, the photocatalytic activity of $\mathbf{1}$ was also confirmed, when the complex was adsorbed onto a heterogeneous matrix in a three components system with 1 as catalyst, $\left[\mathrm{Ru}^{\mathrm{II}}(\mathrm{bpy})_{3}\right]^{2+}$ as photosensitizer, and $\mathrm{Na}_{2} \mathrm{~S}_{2} \mathrm{O}_{8}$ as sacrificial electron acceptor [53]. However, the experiments with 1 /clay adsorbate have been questioned by findings that show that when $\mathbf{1}$ is supported on montmorillonite clay and using $\mathrm{Ce}^{\mathrm{IV}}$ as the chemical oxidant, the actual water oxidation catalyst are layered type Mn-oxide particles [54].

Electrochemical studies of $\mathbf{1}$ in the presence of acetate buffer show that the potential for oxidation of $\mathbf{1}$ can be decreased compared with experiments in aqueous solution. It also reveals proton-coupled electrontransfer reactivity analogous to the OEC. When the electrochemical oxidation of $\mathbf{1}$ is carried out in aqueous solution, appearance of a tetramer is observed, via formation of a mono- $\mu$-oxo bridge, preventing 1 to function as a catalyst [51]. However, almost all published procedures for oxygen evolution catalysis with $\mathbf{1}$ are done in the presence of acetate buffer $[5,47,55]$. Besides, the tetramer has been suggested to evolve $\mathrm{O}_{2}$ electrochemically by reaction with water [56].

Ultimately, the oxygen transfer agent is required in the peroxymonosulfate binding step, which occurs prior to the $\mathrm{O}-\mathrm{O}$ formation. The first oxidation does not require an oxygen transfer agent, as it was observed to occur electrochemically [57]. The second oxidation was only observed with oxygen transfer agents. The highest oxidized species becomes the actual catalyst that undergoes water splitting. From this point, it can be considered as a functional model of the OEC. This is the portion of the reaction that is analyzed in this investigation. As the natural water splitting system PSII generates molecular di-oxygen from water, the most relevant mechanism related to the natural process is one in which both reactant oxygen atoms come from water. Hence, in this investigation we will concentrate only in the catalytic mechanism of water splitting.

The mechanisms of the $\mathrm{O}_{2}$-evolving reaction catalyzed by 1 described by Limburg et al. are mainly based on observations in which $\mathrm{HSO}_{5}^{-}$is used as the oxidant [6]. In those cases, the $\mathrm{pH}$ of the solution was kept at 4.5, using an $\mathrm{AcOH} / \mathrm{AcO}^{-}$buffer. The concentrations of the acetate species at this $\mathrm{pH}$ are $\left[\mathrm{AcO}^{-}\right]=410^{-5} \mathrm{M}$, and $[\mathrm{AcOH}]=$ $710^{-5} \mathrm{M}$, which makes both species available along the whole reaction process.

Water was commonly assumed to be ligated to both Mn centers [58-60]. However, aside from $\mathrm{pH}$ regulation, the presence of acetate plays a key role in the catalyzed reaction of oxygen formation $[5,47,55]$. Using electrochemistry, Brudvig et al. concluded that acetate displaces one of the water Mn ligands. In particular, acetate is proposed to bind to $\mathrm{Mn}^{\mathrm{IV}}$, blocking the ligand-binding site at the highest oxidation state metal [57]. Acetate binding to only one Mn was also reproduced by computational models [61,62]. The ligand at the other Mn center can be either oxone or water. In this report we will only consider the case of a water ligand, to allow a closer parallelism with PSII.

The experimental reaction rate for the $\mathrm{O}-\mathrm{O}$ formation corresponds to a barrier of $19-21 \mathrm{kcal} / \mathrm{mol}$. This barrier actually impose an upper limit to this investigation, as the rate-determining step during turnover was established to be the formation of the highest oxidation state $[6,50]$, or peroxymonosulfate binding [63], occurring prior to the $\mathrm{O}-\mathrm{O}$ bond formation. Several theoretical studies examined the mechanism of the $\mathrm{O}-\mathrm{O}$ bond formation $[60,64,65]$. Among these studies, P. Siegbahn and coworkers address the analysis of the catalytic properties of the terpy complex (1) for this reaction [59,66]. In that study, the calculated barrier for $\mathrm{O}-\mathrm{O}$ formation turns out to be higher than $23 \mathrm{kcal} / \mathrm{mol}$, being probably too high compared with the experimental value.

In this report we present a plausible pathway for water oxidation in the terpy complex based on DFT-B3LYP calculations. The proposed reaction pathway follows several steps that give place to the formation of an $\mathrm{O}_{2} \mathrm{H}^{-}$peroxide intermediate species, and molecular bi-oxygen. This calculation involves a spin rearrangement during the $\mathrm{O}-\mathrm{O}$ bond formation step, which reduces the barrier in $>15 \mathrm{kcal} / \mathrm{mol}$ [67], as compared with previously published results $[59,66]$.

The paper is organized as follows. Section 2 introduces the theoretical background for the calculation of stationary point configurations and free energies. It also includes the electronic structure of selected species present in the $\mathrm{O}_{2}$ reaction. Section 3 includes results of the mechanistic aspects of the triplet-oxygen formation catalyzed by the terpy complex, with emphasis on the relation with the related process in the natural system PSII. Section 4 contains a discussion of the relation between the energetic and electronic structure results presented in the previous sections. Conclusions are presented in Section 5.

\section{Methods}

\subsection{Molecular models}

The X-ray atomic coordinates of the Mn complexes were obtained from the Cambridge Crystallographic Data Center (CCDC) with reference codes FIQFIU [5]. Fully optimized molecular structures were obtained through minimum- or transition state (TS)-geometry optimizations in a broken symmetry (BS) state $[68,69]$. In this state the $\alpha$ and $\beta$ densities are allowed to localize on different atomic centers providing a multiconfigurational character to the spin state. Each step of the above protocol is checked for stability of the Density Functional Theory (DFT) wavefunction. The ionic spin states were characterized according to the analysis of Mulliken atomic spin density populations. Preparation of the models was subject to the constraints of total charge 
and total spin multiplicity, consistent with experimental data. Different arrangements of individual spin states were analyzed by relaxing the molecular structures from appropriate initial-guess spin-electronic states, based on ligand field theory [70].

All steps of the catalytic cycle and the $\mathrm{O}_{2}$ formation reaction are calculated in water solvent, using the Polarizable Continuum Model (PCM) with the integral equation formalism variant [71]. Frequency calculations are used to characterize the structures as local minima (all real frequencies), or first-order saddle points, i.e. transition states (one single imaginary frequency for the correct mode). Transition states are located by initially running a stepwise geometry scan between two local minima by varying the reaction coordinate in a full geometry optimization with one degree of freedom fixed. The maximum point of these geometry scans is used as a starting point for transition state optimizations via Synchronous Transit-guided Quasi-Newton (STQN) methods [72,73]. This approach ensures that the transition state indeed connects the minima at each side of the barrier. Further confirmation is achieved analyzing the normal mode associated with the imaginary frequency. These methods have been shown to accurately reproduce structures and free energies of activation of reaction processes of metal-oxo reactions [74].

Optimizations are done with the unrestricted B3LYP $[75,76]$ density functional method with a basis set constructed as a combination of LACVP on Mn and 6-31+G(d) on the rest of the atoms. This functional is known to perform well in the study of catalytic properties of the oxygen-evolving complex of PSII $[77,78]$, as well as in related inorganic complexes $[43,60,61,79]$. Geometry optimizations and single point calculations use the Gaussian 09 software package [80]. Spin and electronic densities were generated using Gaussian 09 cube files, and plotted with Visual Molecular Dynamics (VMD) visualization computer program $[81,82]$.

\subsection{Free energies}

All optimizations are carried out in liquid phase to avoid artifacts that may arise from eventually different protonation states in the gas and liquid phases, or when stationary points present in liquid solution may not exist in the gas phase [83-85]. One problem with this approach is that optimizations and single point calculations in solvent require longer computational times, and this is aggravated by the number of trial calculations usually necessary to find stationary point configurations, combined with several possible protonation and spin states.

Calculations of solution equilibrium free energies make use of Eq. (1) where $G_{\text {soln }}$ is the solution Gibbs free energy change of the reaction [86]. The values of $G_{\text {soln }}$ of each reactant and product are obtained according with the standard Born-Haber thermodynamic cycle, by adding the thermal correction to the Gibbs free energy $\left(G_{\text {corr-soln }}\right)$, the total energy calculated without temperature correction $\left(E_{\text {soln }}\right)$, and the solvation free energy $G_{\text {solv }}$ as indicated in Eq. (1).

$G_{\text {soln }}=E_{\text {gas }}+G_{\text {corr-soln }}+G_{\text {solv }}$

In this case, $\Delta G_{\text {soln }}$ can be calculated from the difference in $G_{\text {soln }}$ of the products and reactants:

$\Delta G_{\text {soln }}=\sum G_{\text {soln }}($ products $)-\sum G_{\text {soln }}($ reactants $)$

The electronic energy contributions were computed by single-point calculations in gas phase $\left(E_{\text {gas }}\right)$. The free energy corrections $\left(G_{c o r r-s o l n}\right)$, which include enthalpic and entropic terms, and zero point energy (ZPE) corrections, are determined within the rigid rotor-harmonic oscillator approximation (RRHO) from frequency calculations at the B3LYP/6-31G(d) level on aqueous-phase optimized structures.

The solvating effect of the aqueous medium was taken into account through the SMD (Solvation Model D, where the "D" stands for "density", to denote that the full solute electron density is used without defining partial atomic charges) polarizable continuum model $\left(G_{\text {solv }}\right)$ [87] (see Section SI.1 in SI).

The energy differences of intermediates and transition states are sometimes very small, particularly TS associated with proton transfers. These differences usually lie within the error of the DFT methodology. For that reason, we will use enthalpy differences through the text, and present free energies only when they predict a different reaction step. This will allow us to corroborate the actual course of the reaction, as predicted by Gibbs free energies.

\section{Results}

We are interested in the mechanistic aspects of the triplet-oxygen evolution relevant to the similar process in the natural system PSII. A proposal for the whole catalytic cycle based on the findings of Limburg et al. [6] is shown in Fig. 2. As the oxidant (oxone or hypochlorite) has not been observed as a radical, it follows that each step of the cycle consists of a double oxidation.

In the following subsections, we will separate the reaction in three step sequences, each of which describing basically an oxidation event. The first is the sequence that involves the $\mathrm{O}-\mathrm{O}$ bond formation step, which goes from the first reactant to the first product, dubbed R1 to P1 (Section 3.1.3). The second is the sequence that starts from hydroperoxo to give the superoxide ion, $\mathbf{R} 2$ to $\mathbf{P 2}$ (Section 3.1.4). The third is the formation of paramagnetic dioxygen from the superoxide radical, named $\mathbf{R} 3$ to $\mathbf{P 3}$ (Section 3.1.5).

\subsection{Triplet di-oxygen evolution}

\subsubsection{Oxidation state of the catalyst and reactants at the beginning of the reaction}

A high-valent $\mathrm{Mn}(\mathrm{III}, \mathrm{IV})$ state is confirmed by calculations to be the most stable state of the catalyst dimer. From this state, a double oxidation of the Mn complex concerted with deprotonation of one water ligand gives a state with the two manganese centers in oxidation state IV and a stripped-water oxygen in a partial radical state ligated to $\operatorname{Mn}(1)$. After exchange with the chemical oxidant, the system undergoes several oxidant-driven oxidation steps along the catalytic cycle, and reaches the highest oxidation state achieved in the cycle, which is formally described as $\operatorname{Mn}(1)^{\mathrm{V}}-\mathrm{Mn}(2)^{\mathrm{IV}}$. Every attempt to isolate a manganese in oxidation state V by DFT calculations fails, due to the absence of ligands strong enough to keep such high

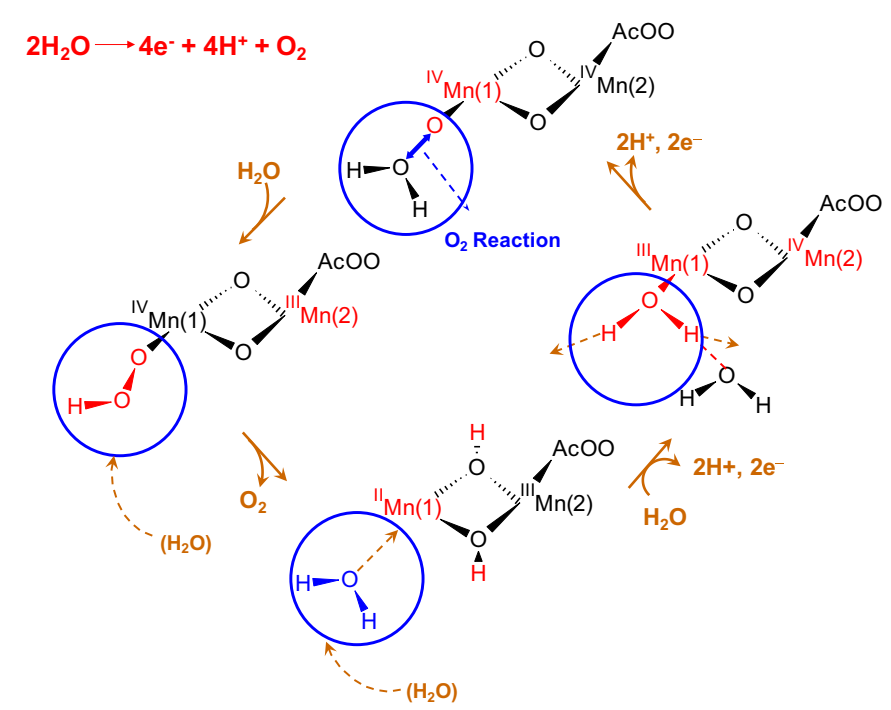

Fig. 2. Proposed mechanism for the reaction between $\mathbf{1}$ and water. Terpy ligands are omitted for clarity. The figure has been adapted from Limburg et al. [6], with updated findings from Cady et al. [57]. 
Table 1

Binding energies of $\mathrm{AcOOH}$ and $\mathrm{H}_{2} \mathrm{O}$ hydrogen bonded to $\mu-\mathrm{O}$ ligands.

\begin{tabular}{|c|c|c|c|c|c|}
\hline \multirow[t]{3}{*}{ Reaction state $^{\mathrm{a}}$} & \multirow[t]{3}{*}{ Mn oxidation state } & \multicolumn{4}{|c|}{ Binding energy $[\mathrm{kcal} / \mathrm{mol}]$} \\
\hline & & \multicolumn{2}{|c|}{$\mathrm{AcOOH}$} & \multicolumn{2}{|l|}{$\mathrm{H}_{2} \mathrm{O}$} \\
\hline & & $\mathrm{O}(3)$ & $\mathrm{O}(4)$ & $\mathrm{O}(3)$ & $\mathrm{O}(4)$ \\
\hline R1 & $\operatorname{Mn}(I V, I V)$ & 10.72 & 10.96 & 11.00 & 8.77 \\
\hline P1/R2 & $\operatorname{Mn}(\mathrm{IV}, \mathrm{III})$ & 12.84 & 11.96 & 10.29 & 12.07 \\
\hline P2/R3 & $\operatorname{Mn}(\mathrm{III}, \mathrm{III})$ & 15.58 & 15.84 & 13.66 & 12.44 \\
\hline
\end{tabular}

a See Figs. 3 and 4 for the different reaction states.

oxidation state [88]. This state is the initial step of the di-oxygen evolution reaction. As reported elsewhere $[41,59,66,89]$, the oxidation at position (1) is ligand centered rather than metal centered. In those previous reports, the oxidation state is best described as $\mathrm{O}(5)^{\mathrm{I}}$ $\mathrm{Mn}(1)^{\mathrm{IV}}-\mathrm{Mn}(2)^{\mathrm{IV}}$, including $\mathrm{O}(5)$ as an oxyl radical. However, although both high- and low-spin $\mathrm{Mn}^{\mathrm{V}}$-oxo species are known experimentally, support for the $\mathrm{Mn}^{\mathrm{IV}}$-oxyl comes exclusively from DFT calculations. In our investigation, we found unpaired spin density associated with the oxido ligand of $\mathrm{Mn}$ ( 1 ) (0.44 spins), yet the density is less than what is expected from an oxyl radical (one spin).

\subsubsection{Molecular environment around the catalyst}

The reaction environment includes proton donor species such as AcOOH and $\mathrm{H}_{2} \mathrm{O}$, which can form hydrogen bonds among themselves, as well as with the oxo-bridge ligands. Assuming a simple model based on the Boltzmann distribution, we found that there is $98 \%$ probability of finding $\mathrm{AcOOH}$ at $\mathrm{O}(4)$ compared with water in the initial step of the reaction (Table 1 ). Conversely, at $\mathrm{O}(3)$ there is a slight preference for water. The increased water affinity to $\mathrm{O}(3)$ compared to $\mathrm{O}(4)$ arises from the water molecule having an additional stabilizing electrostatic interaction with the acetate ligand of $\operatorname{Mn}(2)$, which is not present in the $\mathrm{O}(4)$ position (see Fig. S1 in $\mathrm{SI}$ ). The binding energy of $\mathrm{AcOOH}$ to the oxo-bridge ligands in the $\mathrm{Mn}^{\mathrm{IV}}-\mathrm{Mn}^{\mathrm{IV}}$ state is $>10 \mathrm{kcal} / \mathrm{mol}$, which is considerably higher than the typical $\mathrm{O}-\mathrm{H}$...: $:$ interaction of $5.0 \mathrm{kcal} / \mathrm{mol}$ among solvent molecules. This energy difference suggests that an $\mathrm{AcOOH}$ molecule will usually be hydrogen bonded to an oxobridge ligand in the first step of the $\mathrm{O}-\mathrm{O}$ bond formation reaction.

\subsubsection{0 - O bond formation}

In this stage, a water molecule from the bulk approaches the water ligand of $\mathrm{Mn}(1)$, which at this stage is a completely deprotonated oxido ligand (R1, Fig. 3). After deprotonation of the approaching water molecule and spin rearrangement, hydrogen peroxo is formed (P1). Mechanistically, deprotonation and $\mathrm{O}-\mathrm{O}$ bond formation can occur either in a concerted or in a stepwise mechanism. The latter imposes a less stringent arrangement, and hence suggests lower energy barriers.

Different molecular species can serve as the base responsible for proton abstraction of the water molecule, including the $\mu$-oxo ligands, acetate ion from the solution, or a bulk water molecule. Direct proton transfer to the oxo-bridge ligands is impeded, as the bridging ligand position is capped by an $\mathrm{AcOOH}$ from the solution, which decreases the probability of direct proton transfer to the oxo-bridge ligands.* Among the other two proton abstractor candidates, $\mathrm{AcOO}^{-}$is better base than water, which makes a bulk acetate ion the best candidate for proton abstraction, as established by previous results [62].

3.1.3.1. Alternative $\mathrm{O}-\mathrm{O}$ bond formation mechanism with protonation of the $\mu$-O bridging ligand. Although proton transfer to an $\mathrm{AcOO}^{-}$in solution is the mechanism maximally consistent with the surrounding conditions of the catalyst ( $\mathrm{AcOOH}$ capping the oxo ligand), this mechanism

An indirect protonation is also possible in which the $\mathrm{AcOOH}$ molecule receives a proton from the reactant water molecule, and transfers its proton to the $\mu-\mathrm{O}$ ligand, in a concerted mechanism (see Section 3.2.3.1). is qualitatively different to some recent proposals of water splitting in PSII based on real time X-ray laser spectroscopy, in which protonation of a $\mu-\mathrm{O}$ bridging ligand is proposed as part of the $\mathrm{O}-\mathrm{O}$ bond formation step $[90,91]$.

To further analyze this option, alternative approaches that entail protonation of the $\mu$-oxo ligand $\mathrm{O}(4)$ are also considered. This protonation can be achieved in two different ways. One is direct transfer from the attacking water molecule to $\mathrm{O}(4)$. The product of this alternative mechanism is approximately $11 \mathrm{kcal} / \mathrm{mol}$ less stable than transfer to a bulk acetate anion. The second is an indirect transfer, and involves proton transfer of the attacking water molecule to an $\mathrm{AcOO}^{-}$ion H-bonded to $\mathrm{O}(4)$, and proton transfer from acetate to $\mathrm{O}(4)$. In this alternative arrangement, one of the oxygens of the $\mathrm{AcOO}^{-}$is proton acceptor of two simultaneous hydrogen bonds, one from the $\mathrm{OOH}^{-}$peroxide ligand and the second from the $\mathrm{OH}$ bridging ligand (Fig. S2 in SI). For this reason, each proton forms a weaker hydrogen bond, and it does not extract the proton from the $\mathrm{OH}$ bridging ligand, as is the case with single H-bonded acetate.

This arrangement is approximately $10 \mathrm{kcal} / \mathrm{mol}$ less stable than a setup in which acetic acid is hydrogen bonded to $\mathrm{O}(4)$, and has no interactions with the hydroperoxo ligand. Hence, from an energetic perspective, the bridging ligand must be deprotonated at this stage of the reaction.

\subsubsection{Formation of superoxide}

This step involves reduction of $\mathrm{Mn}$ (IV,III) to $\mathrm{Mn}$ (III,III) (R2 to P2), and deprotonation of the $\mathrm{OOH}$ peroxo formed in the previous R1 to P1 step (Fig. 4).

The $11.96 \mathrm{kcal} / \mathrm{mol}$ binding enthalpy of $\mathrm{AcOOH}$ to $\mathrm{O}(4)$ in the $\mathrm{Mn}(\mathrm{IV}, \mathrm{III})$ oxidation state of $\mathbf{R} \mathbf{2}$ is higher than in the $\mathrm{Mn}(\mathrm{IV}, \mathrm{IV})$ state in R1. Similarly, the $12.84 \mathrm{kcal} / \mathrm{mol}$ binding affinity of $\mathrm{AcOOH}$ to $\mathrm{O}(3)$ in $\mathbf{R} \mathbf{2}$ is also higher than in $\mathbf{R} \mathbf{1}$ (Table 1). This suggests that $\mathrm{AcOOH}$ remains $\mathrm{H}$-bonded to the $\mu-\mathrm{O}$ ligand in the current step. The reduction of the manganese centers in going from $\mathbf{R} \mathbf{1}$ to $\mathbf{R} \mathbf{2}$ decreases charge transfer from the oxo-bridge ligands to the metals, which contributes to the concentration of electron density on the bridging moieties. This effect contributes to raise the affinity of proton donor species to the $\mu-O$ ligands.

Two molecular groups can act as bases that grab the transferred proton from the $\mathrm{OOH}$ peroxo, the oxo-bridge ligands, or acetate from the solution. DFT computations confirm that the final oxidation state $\mathrm{Mn}(\mathrm{III}, \mathrm{III})$ of $\mathbf{P 2}$ is either consistent with a single-protonated bridge [62], or a non-protonated bridge (Table 2). When the $\mathrm{AcOOH}$ is hydrogen bonded to $\mathrm{O}(4)$, the configuration with the protonated acetate is $1 \mathrm{kcal} / \mathrm{mol}$ more stable than the $\mathrm{AcOO}^{-} / \mathrm{HO}(4)$ hydrogenbond arrangement. However, the enthalpy barrier of proton transfer from $\mathrm{AcOOH}$ to the $\mathrm{O}(4)$ bridging ligand is $1.33 \mathrm{kcal} / \mathrm{mol}$, while the inverse transfer from $\mu-\mathrm{OH}$ to $\mathrm{AcOO}^{-}$is only $0.33 \mathrm{kcal} / \mathrm{mol}$. This means that at room temperature, the proton can be transferred from the bridge to the $\mathrm{AcOO}^{-}$, while proton transfer in the opposite direction will be hindered.

It is also feasible to consider an alternative protonation mechanism of the bridge in which the $\mathrm{AcOOH}$ hydrogen bonded to $\mathrm{O}(3)$ protonates the bridge. Once $\mathrm{O}(3)$ is protonated, the $\mathrm{AcOO}^{-}$ligand of $\mathrm{Mn}(2)$ will form a $\mathrm{H}$-bond with the protonated $\mathrm{O}(3)$, preventing the proton to be transferred back to the solution. The configuration with $\mathrm{ACOOH}$ hydrogen bonded to $\mathrm{O}(3)$ is only $1 \mathrm{kcal} / \mathrm{mol}$ more stable than the hydrogen bond pair $\mathrm{AcOO}^{-} / \mathrm{O}(3) \mathrm{H}$. However, as in the case of $\mathrm{O}(4)$, the barrier to proton transfer from $\mathrm{AcOOH}$ to $\mathrm{O}(3)$ is $1.15 \mathrm{kcal} / \mathrm{mol}$, while the reverse transfer is much smaller at $0.20 \mathrm{kcal} / \mathrm{mol}$. We will hence consider only the more stable configuration of $\mathrm{AcOOH}$ hydrogen bonded to $\mathrm{O}(3)$. An unprotonated $\mathrm{O}(3)$ is consistent with previous studies [62].

From a strictly energetic point of view, proton transfer to a bulk $\mathrm{AcOO}^{-}$is $4.75 \mathrm{kcal} / \mathrm{mol}$ more stable than proton transfer from the attacking water to $\mathrm{O}(4)$. In addition, direct protonation of $\mu-\mathrm{O}$ ligands in the current step is additionally hindered, as it incurs an energy 


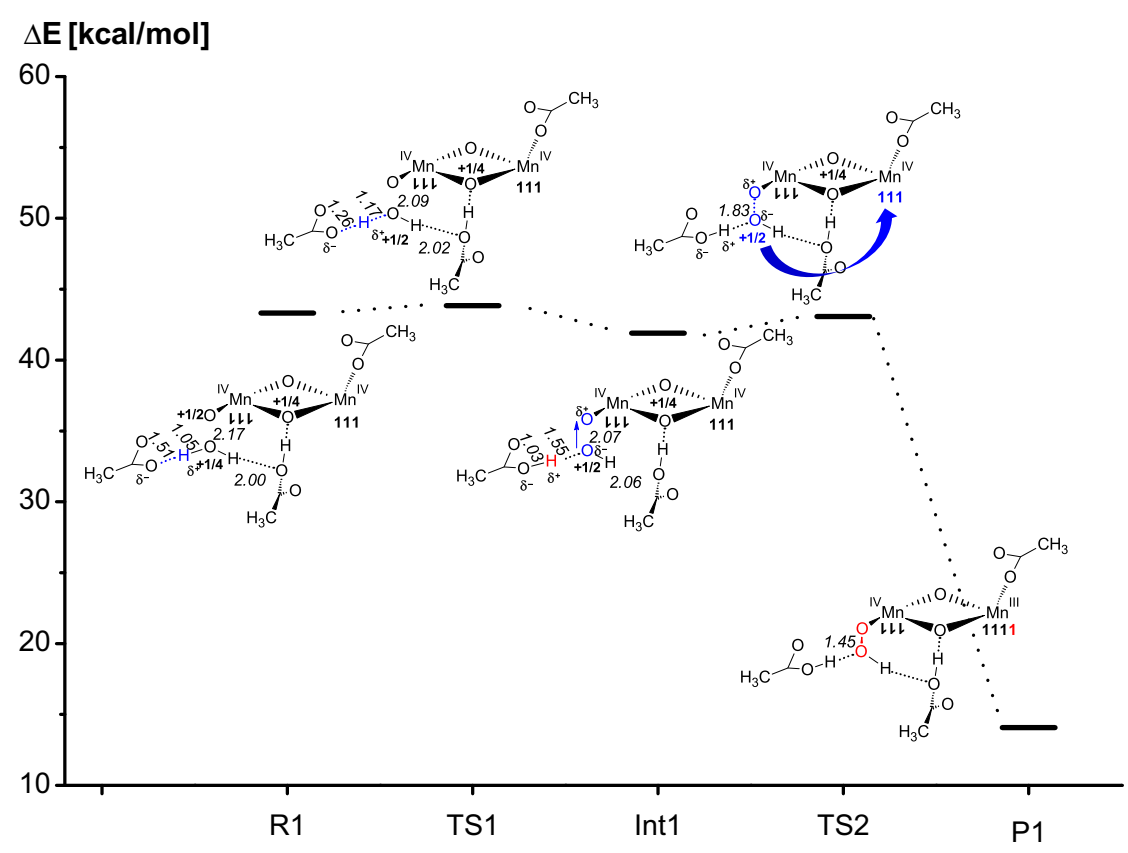

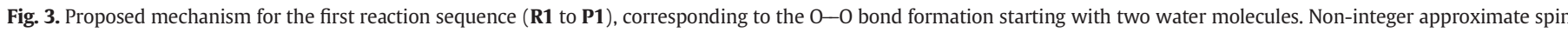

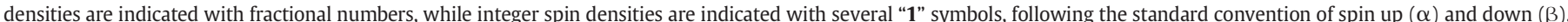

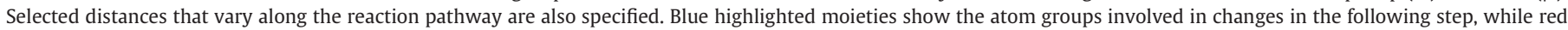
highlighted atom groups indicate moieties that changed with respect to the previous step. Terpy ligands are omitted for clarity.

penalty of $>10 \mathrm{kcal} / \mathrm{mol}$. This energy is required to break the H-bond between $\mathrm{AcOOH}$ and $\mu-\mathrm{O}$, prior to proton transfer. Besides, if proton transfer to $\mathrm{O}(4)$ occurs, the proton will be captured back by a bulk $\mathrm{AcOO}^{-}$, thus in both mechanisms the proton transferred from the $\mathrm{OOH}$ will end up being in a solution acetate.

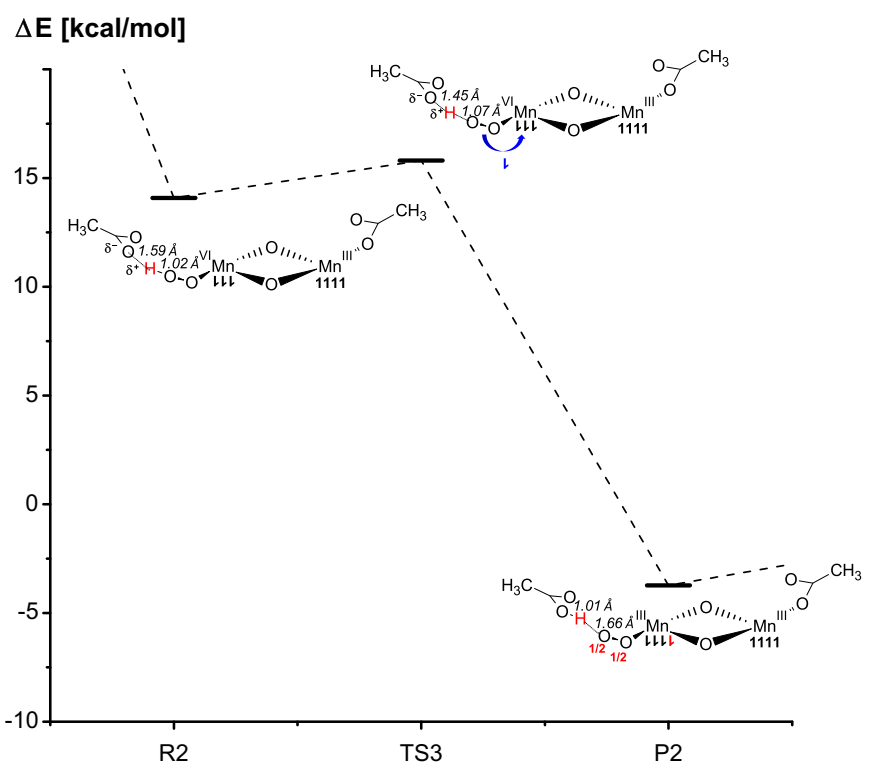

Fig. 4. Proposed mechanism for the second reaction sequence ( $\mathbf{R} 2$ to P2), corresponding to the second oxidation event that leads to superoxide anion formation. Non-integer approximate spin densities are indicated with fractional numbers, while integer spin densities are indicated with several "1" symbols, following the standard convention of spin up $(\alpha)$ and down $(\beta)$. Selected distances that vary along the reaction are also specified. Blue highlighted moieties show the atom groups involved in changes in the following step, while red highlighted atom groups indicate moieties that changed with respect to the previous step. Terpy ligands are omitted for clarity, as well as acetate, which has a passive role in this sequence.
All these considerations show that direct proton transfer from the attacking $\mathrm{OOH}$ to a bulk $\mathrm{AcOO}^{-}$is the most straightforward and energetically more favorable mechanism for this reaction step. After proton transfer, a superoxide radical $\left(\mathrm{O}_{2}^{-} \cdot\right.$, with spin densities 0.47 and 0.57 associated with each oxygen atom) is formed, ligated to $\mathrm{Mn}(1)$ (Fig. 5).

\subsubsection{Molecular di-oxygen formation $\left({ }^{3} \mathrm{O}_{2}\right)$}

In this step, the $\mathrm{Mn}(1)$ superoxide radical ligand is oxidized, with concomitant reduction of manganese (from Mn(III,III) in R3 to Mn(II,III) in $\mathbf{P 3}$, to release the molecular paramagnetic dioxygen final product $\left({ }^{3} \mathrm{O}_{2}\right)$ (see Table 3 ).

Whereas the $\mathrm{Mn}(\mathrm{III}, \mathrm{III})$ oxidation state in $\mathbf{R} \mathbf{3}$ does not require protonation of the bridge, a reduced $\mathrm{Mn}(\mathrm{II}, \mathrm{III})$ state requires the bridge to be double protonated (single protonation is not consistent with this reduced state). As the reaction progresses, there is a reduction of the oxidation state of the metals, and a concomitant increase of the binding enthalpy of proton donor groups hydrogen bonded to the $\mu-\mathrm{O}$ bridging ligands (Table 1 ). This increase ultimately creates a covalent bond between the hydrogen and the oxo-bridging ligands in the final Mn(II,III) state (P3).

The proton transfer can be achieved with both protons transferred from $\mathrm{AcOOH}$ to the oxo bridging ligands with a concerted mechanism, or in a stepwise mechanism. The latter can be done in two different ways, according to the order in which the proton is transferred to each oxo-bridge ligand. Protonation of the oxo-bridge ligands is essentially

Table 2

Spin densities consistent with different protonation states of the $\mu-\mathrm{O}$ ligands.

\begin{tabular}{lll}
\hline Protonation state of bridging ligands & \multicolumn{2}{l}{ Spin density } \\
\cline { 2 - 3 } & $\mathrm{Mn}(1)$ & $\mathrm{Mn}(2)$ \\
\hline $\mathrm{O}(3), \mathrm{O}(4)$ & -3.85 & 3.84 \\
$\mathrm{HO}(3), \mathrm{O}(4)$ & -3.91 & 3.83 \\
$\mathrm{O}(3), \mathrm{HO}(4)$ & -3.95 & 3.83 \\
$\mathrm{HO}(3), \mathrm{HO}(4)$ & -4.81 & 3.86
\end{tabular}




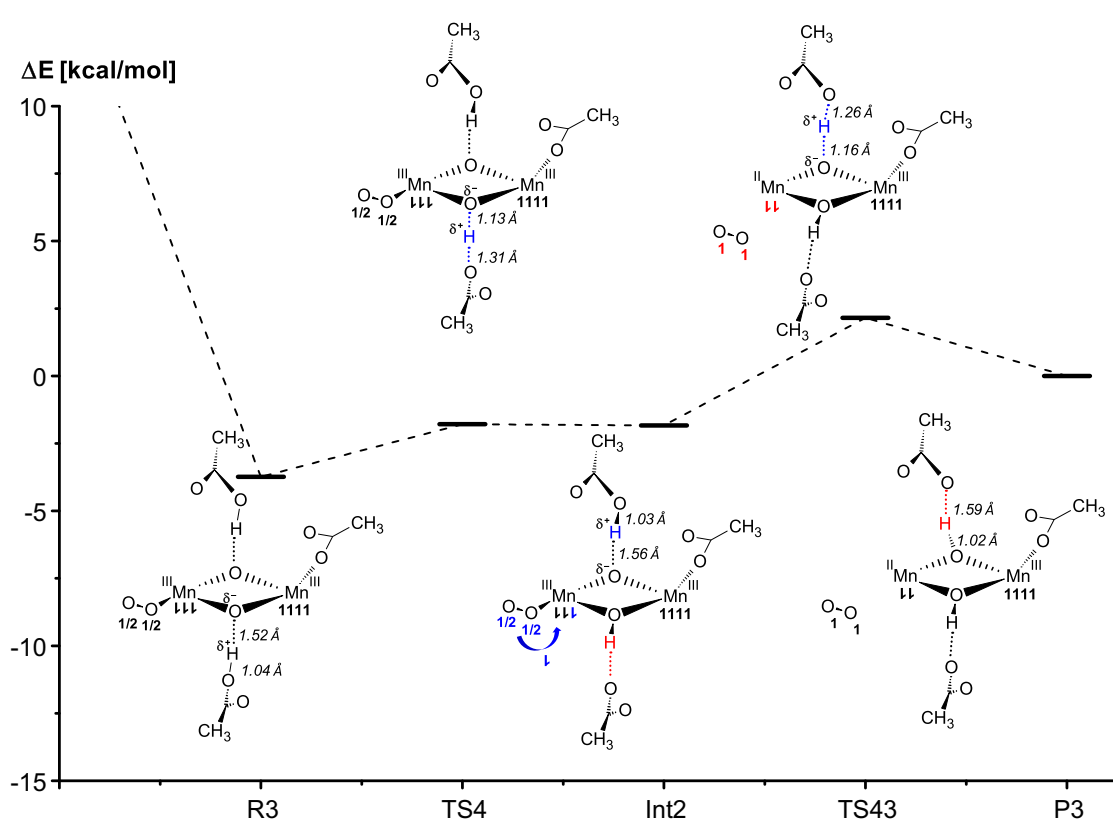

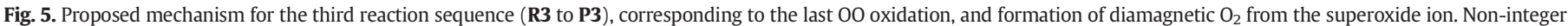

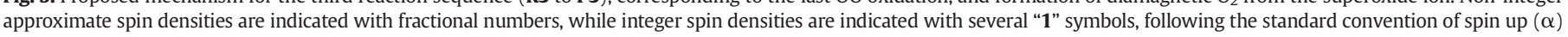

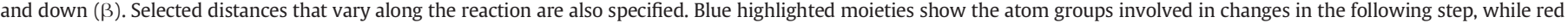
highlighted areas indicate moieties that changed with respect to the previous step. Terpy ligands are omitted for clarity.

barrier-less for both oxo-bridge ligands; showing that both mechanisms can be simultaneously operative.

Enthalpy differences in this oxidation-reduction step are very small, and do not entail reduction of the energy along the reaction path. The corresponding free energies are close together, but they give a definite lower value for the final product (Table S1 in SI). This is due to the weakening of the $\mathrm{Mn}(1)-\mathrm{O}_{2}$ bond induced by the trans-standing hydroxo groups renders the final desorption step to be entropy driven. It is clear that, from an entropic point of view, the $\mathrm{Mn}-\mathrm{O}-\mathrm{O}$ subunit benefits significantly by acquiring a quasi-degenerate rotational degree of freedom.

\subsection{Electronic structure properties along the reaction pathway}

The analysis of the topology of spin and electron density surfaces helps to understand more clearly the details of spin transfer between

Table 3

Spin populations of stationary states along the $\mathrm{O}_{2}$ evolution reaction.

\begin{tabular}{|c|c|c|c|c|c|}
\hline \multirow[t]{2}{*}{ Reaction state } & \multicolumn{5}{|c|}{ Mulliken spin density } \\
\hline & $\operatorname{Mn}(1)$ & $\operatorname{Mn}(2)$ & $\mathrm{O}(5)$ & $\mathrm{O}(6)$ & $\mathrm{O}(3)$ \\
\hline R1 & -2.64 & 2.69 & 0.44 & 0.30 & 0.26 \\
\hline TS1 & -2.59 & 2.67 & 0.25 & 0.43 & 0.29 \\
\hline Int 1 & -2.50 & 2.64 & -0.03 & 0.61 & 0.32 \\
\hline Ts2 & -2.26 & 2.63 & -0.12 & 0.44 & 0.33 \\
\hline $\mathbf{P 1}{ }^{a}$ & -2.67 & 3.87 & -0.00 & -0.00 & -0.18 \\
\hline TS3 & -3.27 & 3.85 & 0.28 & 0.19 & - \\
\hline $\mathbf{P 2}^{\mathrm{a}}$ & -3.83 & 3.84 & 0.47 & 0.57 & - \\
\hline TS4 & -3.94 & 3.85 & 0.47 & 0.66 & - \\
\hline Int2 & -3.96 & 3.84 & 0.48 & 0.67 & - \\
\hline TS43 & -4.79 & 3.85 & 1.00 & 1.00 & - \\
\hline $\mathbf{P 3}^{\mathrm{a}}$ & -4.81 & 3.86 & 1.00 & 1.00 & - \\
\hline TS4' & -3.89 & 3.84 & 0.45 & 0.64 & -0.00 \\
\hline Int2' & -3.95 & 3.84 & 0.47 & 0.67 & -0.00 \\
\hline TS34 & -4.81 & 3.86 & 1.00 & 1.00 & -0.02 \\
\hline P3 & -4.81 & 3.86 & 1.00 & 1.00 & -0.02 \\
\hline
\end{tabular}

a Densities correspond to the product. Reactant values of the following step diffe in $<1 \%$. different molecular moieties. In this sub section, differences of spin and electron densities with respect to an initial state are plotted for selected reaction steps. Due to changes in the molecular structure associated with the charge transfer events, the corresponding spin-density differences are only approximate. We adopt the convention of taking the alpha spin as positive, and beta spin negative.

In an octahedral environment, the five $d$ orbitals of manganese are split into a three-fold degenerate $t_{2 g}$ set $\left(d_{x y}, d_{y z}, d_{x z}\right)$ and a two-fold degenerate $e_{\mathrm{g}}$ set $\left(\mathrm{d}_{z}{ }^{2}, \mathrm{~d}_{x}^{2}-{ }^{2}\right)$. In a distorted octahedral environment, the degeneracies are lifted, but the symmetries of the $t_{2 g}$ and $e_{g}$ sets remain. The $t_{2 g}$ orbitals mediate $\pi$ interactions with the ligands, whereas $\mathrm{e}_{\mathrm{g}}$ orbitals mediate $\sigma$ interactions. In the high-spin ground-state of $\mathrm{Mn}^{\mathrm{III}}$ and $\mathrm{Mn}^{\mathrm{IV}}$, all $\alpha 3 \mathrm{~d}$ orbitals are empty, and can contribute to $\sigma$ and $\pi$ bonding. In high-spin $\mathrm{Mn}^{\mathrm{III}}, \beta$ electrons have electron configuration $\left[\mathrm{t}_{2 \mathrm{~g}}\right]^{3}\left[\mathrm{e}_{\mathrm{g}}\right]^{1}$, with only one unoccupied $\mathrm{e}_{\mathrm{g}}$ function available. In $\mathrm{Mn}^{\mathrm{IV}}$, the three $\beta$ electrons occupy $\mathrm{t}_{2 \mathrm{~g}}$ orbitals, so there are two unoccupied $e_{\mathrm{g}}$ functions available. Hence, $\beta$-spin MOs can only contribute to $\sigma$ bonding $\left(e_{g}\right)$.

\subsubsection{R1-TS1-Int1 reaction sequence}

The half spin associated with $\mathrm{O}(5)$ ( 0.44 spins) represents an intermediate situation between the stronger double bond with the nonradical oxygen in $\mathrm{O}=\mathrm{Mn}^{\mathrm{V}}$, and the weaker single bond with the oxyl radical in $0 \cdot-\mathrm{Mn}^{\mathrm{IV}}$. The orbital bonding contributions to the $\mathrm{HOO}-\mathrm{Mn}(1)$ bond in $\mathbf{R} \mathbf{1}$ include $\mathrm{p}_{z}$ orbitals of the oxido ligand, and $\mathrm{d}_{x z}$ orbitals of manganese in 189a MO (Fig. 6), indicating a $\pi$-donor bonding interaction via $\mathrm{p}_{z}+\mathrm{d}_{x z}$ orbital components (Table 4 ). Similarly, the $\mathrm{p}_{y}+\mathrm{d}_{x y}$ orbital components of the $186 \mathrm{a}$ MO form a second $\pi$-donor interaction. The resulting bonding orbitals have $7 \%$ manganese and $21 \%$ oxygen character (189a MO), and $8 \%$ manganese and $17 \%$ oxygen character (186a MO), indicating a very covalent $\pi$-donor ligand-tometal bond. There are additional alpha contributions to the $\mathrm{O}-\mathrm{Mn}(1)^{\mathrm{IV}}$ bond, from 189a, 186a, 192a, 175a and 169a MOs, with metal admixtures of $7 \%, 8 \%, 5 \%, 4 \%$ and $5 \%$, respectively. Beta orbitals contribute small $\sigma$ donor interactions to the empty $\beta \mathrm{e}_{\mathrm{g}}$ orbitals from $173 \mathrm{~b}, 168 \mathrm{~b}$, and 160b MOs. 


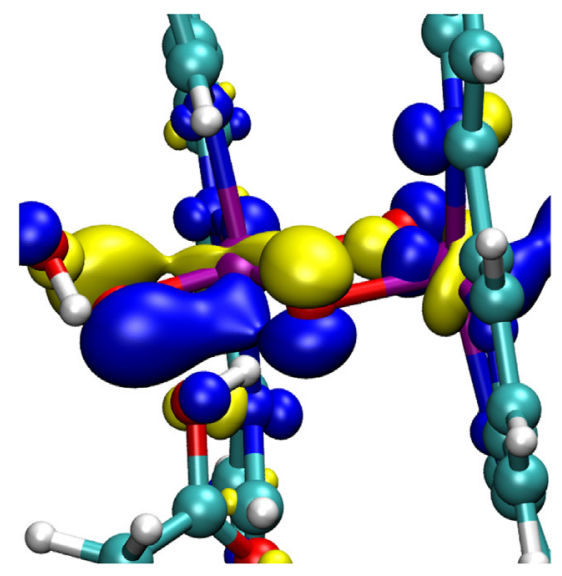

$186 a$

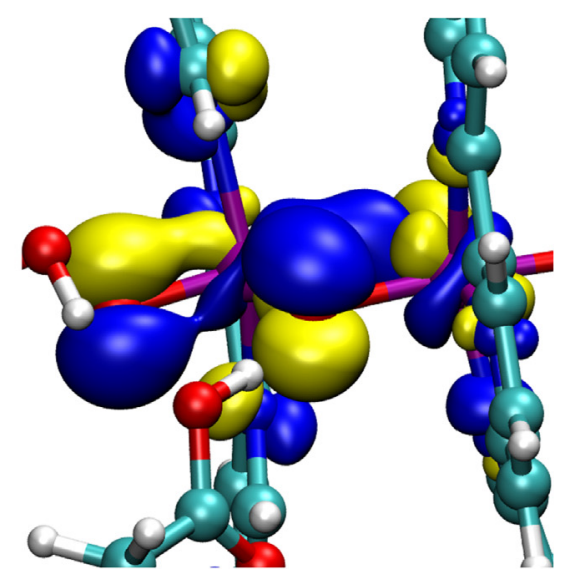

$189 a$

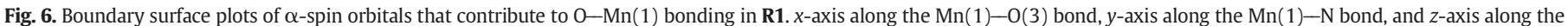
$\mathrm{Mn}(1)-\mathrm{O}(4)$ bond.

Deprotonation of the water molecule triggers electronic redistribution, with accumulation of negative charge on the formed $\mathrm{OH}^{-}$. This moiety is stabilized by hydrogen bonds with bulk acetate, including the acetate $\mathrm{H}$-bonded to $\mu-\mathrm{O}$. The $\mathrm{O}$ ligand of $\mathrm{Mn}(1)$ is highly electrophilic, and attracts charge from the incoming $\mathrm{OH}^{-}$. There is redistribution of $\beta$-spin from the $\mathrm{OH}^{-}$to $\mathrm{O}(5)$, which gives an increase of alpha spin associated with the $\mathrm{OH}^{-}$(0.2 spins in TS1, and another 0.2 spins in Int1), and a reduction of the net spin in $\mathrm{O}(5)$ in this reaction step (Table 3).

Spin density differences in the R1-TS1-Int1 reaction sequence, shows that the net positive spin transfer from $O(6)$ to $O(5)$ entails $p$ orbitals localized on both oxygen atoms, along the $\mathrm{O}-\mathrm{O}$ axis at the $\mathrm{O}(6)$ end, and perpendicular to this axis on $\mathrm{O}(5)$; as well as orbitals of d symmetry localized on $\operatorname{Mn}(1)$, perpendicular to the $\mu$-oxo plane (Fig. 7). Although the net spin transfer is positive, there are no $\alpha$ orbital transitions with the described symmetry in R1. On the other hand, the $\beta$-spin HOMO-LUMO transition involves charge transfer from the attacking water to the oxide ligand. This transfer has both the correct symmetry and spin transfer direction (Fig. 8). The transition corresponds to the 199b, 201b MO pair (200b MO is localized on bulk acetate). The spin transfer in this transition contributes to add $\beta$ density around $\mathrm{O}(5)$, which tends to compensate the excess $\alpha$ density localized around this center at the beginning of the reaction, contributing to the $\mathrm{O}-\mathrm{O}$ bond formation. The $\mathrm{Mn}(1)$ center also plays a role in the spin redistribution, as it acquires positive spin density along the transition to Int1 (0.05 spins in TS1, and 0.10 in Int1).

\subsubsection{Int1-TS2-P1 reaction sequence, the $\mathrm{O}-\mathrm{O}$ bond formation step}

In Int1, the main contribution to the $05-\mathrm{Mn}(1)$ bond comes from the $\alpha$ orbitals. The two most important contributions arise from 201a, and 172a MOs (Table 5), which are essentially $\pi-$ and

Table 4

Charge contributions of important MOs to the $\mathrm{Mn}(1)-\mathrm{O}$ (oxide) bond in $\mathbf{R} \mathbf{1}$

\begin{tabular}{|c|c|c|c|c|c|c|}
\hline \multirow[t]{2}{*}{$\mathrm{MO}^{\mathrm{a}}$} & \multirow[t]{2}{*}{ Orbital components (O-Mn) } & \multirow[t]{2}{*}{ Symmetry } & \multicolumn{2}{|l|}{$\operatorname{Mn}(1)$} & \multicolumn{2}{|c|}{$\mathrm{O}(5)$} \\
\hline & & & $s+p$ & d & S & $\mathrm{p}$ \\
\hline $173 b$ & $\mathrm{p}_{x}-\mathrm{d}_{x}^{2}-y^{2}$ & $\sigma$ & 1 & 1 & 0 & 6 \\
\hline $168 b$ & $\mathrm{p}_{x}-\mathrm{d}_{x}^{2}-y^{2}$ & $\sigma$ & 1 & 2 & 1 & 12 \\
\hline $160 b$ & $\mathrm{p}_{x}-\mathrm{d}_{z}^{2}$ & $\sigma$ & 2 & 7 & 1 & 6 \\
\hline $192 a$ & $\mathrm{p}_{y}-\mathrm{d}_{x z}+\mathrm{d}_{x y}$ & $\pi$ & 1 & 5 & 0 & 15 \\
\hline $189 a$ & $\mathrm{p}_{y}+\mathrm{p}_{z}-\mathrm{d}_{x z}+\mathrm{d}_{y z}$ & $\pi$ & 1 & 7 & 0 & 21 \\
\hline $186 a$ & $\mathrm{p}_{y}+\mathrm{p}_{z}-\mathrm{d}_{y z}+\mathrm{d}_{x y}$ & $\pi$ & 1 & 8 & 0 & 17 \\
\hline $175 a$ & $\mathrm{p}_{x}+\mathrm{p}_{y}+\mathrm{p}_{z}-\mathrm{d}_{x z}+\mathrm{d}_{y z}$ & $\pi$ & 0 & 4 & 0 & 10 \\
\hline $169 a$ & $\mathrm{p}_{y}+\mathrm{p}_{x}+\mathrm{p}_{z}-\mathrm{d}_{x y}+\mathrm{d}_{x}^{2}-y^{2}$ & $\sigma, \pi$ & 1 & 5 & 1 & 20 \\
\hline
\end{tabular}

a $\alpha$-HOMO, $\alpha$-LUMO: 201a, 202a MO; $\beta$-HOMO, $\beta$-LUMO: 199b, 201 b MO. $\sigma$-type bonding orbitals, respectively (Fig. 9). In the 201a MO, the $\alpha$-spin HOMO, the bonding contribution comes from the $\mathrm{p}_{y}+\mathrm{d}_{x y}$ and $\mathrm{p}_{z}+\mathrm{d}_{x z}$ orbital bonding combinations; while in 172a MO, it arises from the $\mathrm{p}_{x}+\mathrm{d}_{x}{ }^{2}-y^{2}$ orbital bonding combination. The resulting bonding orbitals have $12 \%$ manganese and $27 \%$ oxygen character (201a MO), and $11 \%$ manganese and $14 \%$ oxygen character (172a MO), indicating a very covalent $\sigma, \pi$-donor ligand-to-metal bond contribution from

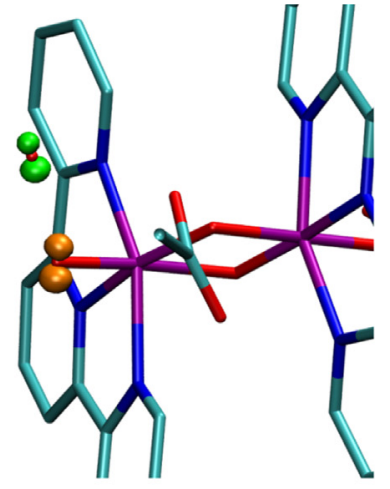

R1 to TS1

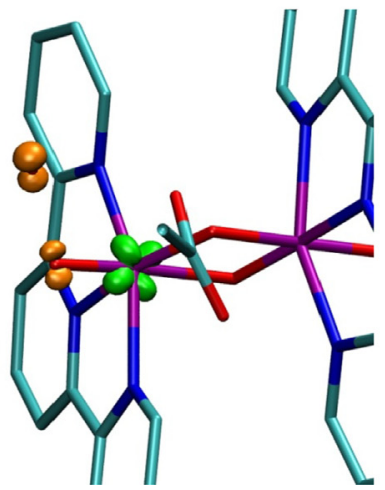

Int1 to TS2

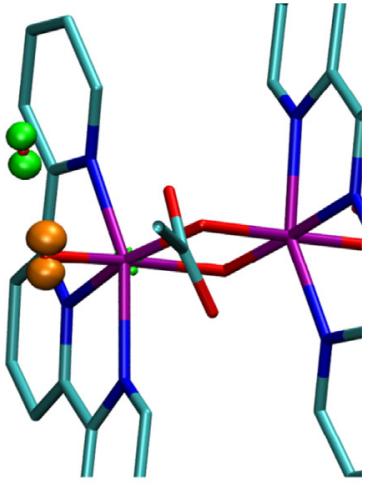

TS1 to Int1

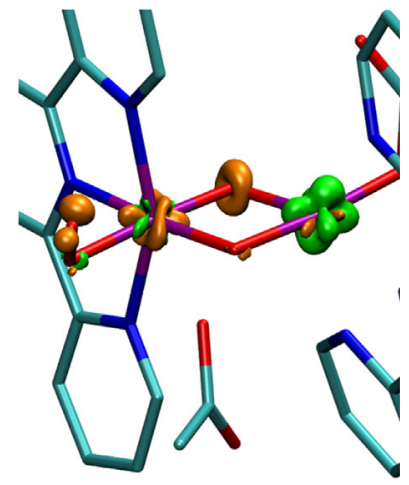

TS2 to P1
Fig. 7. Spin density differences at different stages of the $\mathrm{O}-\mathrm{O}$ bond formation reaction. The densities at different configurations are obtained via subtraction of the last state minus the initial state. Green isosurfaces correspond to more positive spin with respect to the initial state, while orange isosurfaces correspond to a decrease of spin density. 

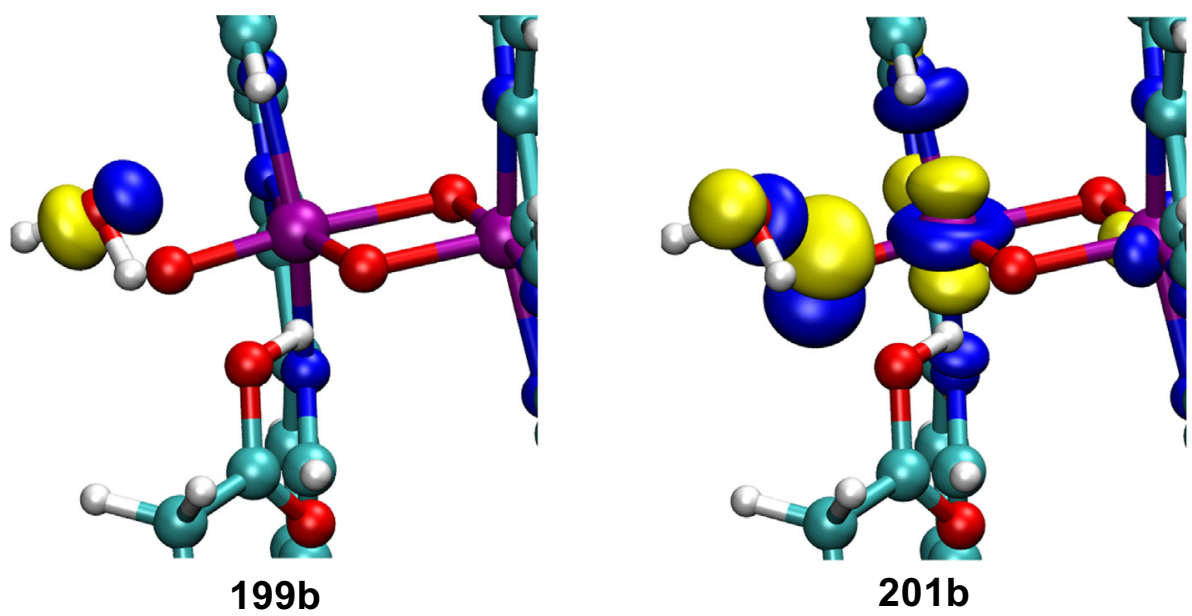

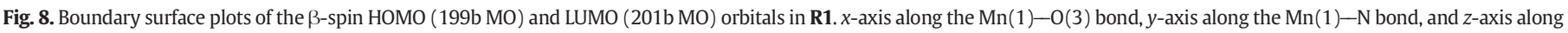
the $\mathrm{Mn}(1)-\mathrm{O}(4)$ bond.

Table 5

Charge contributions of important MOs to the $\mathrm{Mn}(1)-\mathrm{O}$ (oxide) bond in Int1.

\begin{tabular}{|c|c|c|c|c|c|c|}
\hline \multirow[t]{2}{*}{$\mathrm{MO}^{\mathrm{a}}$} & \multirow[t]{2}{*}{ Orbital components ( $\mathrm{O}-\mathrm{Mn})$} & \multirow[t]{2}{*}{ Symmetry } & \multicolumn{2}{|l|}{$\operatorname{Mn}(1)$} & \multicolumn{2}{|c|}{$\mathrm{O}(5)$} \\
\hline & & & $\mathrm{s}+\mathrm{p}$ & d & $\mathrm{s}$ & $\mathrm{p}$ \\
\hline $184 b$ & $\mathrm{p}_{x}-\mathrm{d}_{x}^{2}-y^{2}$ & $\sigma$ & 0 & 1 & 0 & 8 \\
\hline $175 b$ & $\mathrm{p}_{x}-\mathrm{d}_{x}^{2}-y^{2}$ & $\sigma$ & 1 & 1 & 0 & 7 \\
\hline $169 b$ & $\mathrm{p}_{x}-\mathrm{d}_{x}{ }^{2}-y^{2}$ & $\sigma$ & 0 & 2 & 0 & 10 \\
\hline $164 b$ & $\mathrm{p}_{x}-\mathrm{d}_{z}^{2}$ & $\sigma$ & 0 & 6 & 0 & 5 \\
\hline 201a & $\mathrm{p}_{y}+\mathrm{p}_{z}-\mathrm{d}_{x^{2}-y^{2}}+\mathrm{d}_{x z}+\mathrm{d}_{x y}$ & $\pi$ & 1 & 12 & 0 & 27 \\
\hline 196a & $\mathrm{p}_{x}+\mathrm{p}_{y}+\mathrm{p}_{z}-\mathrm{d}_{x y}$ & $\pi$ & 1 & 3 & 0 & 11 \\
\hline $193 a$ & $\mathrm{p}_{y}+\mathrm{p}_{z}-\mathrm{d}_{x z}$ & $\pi$ & 0 & 4 & 0 & 10 \\
\hline 191a & $\mathrm{p}_{y}+\mathrm{p}_{z}-\mathrm{d}_{x z}+\mathrm{d}_{x y}$ & $\pi$ & 1 & 6 & 0 & 18 \\
\hline $172 \mathrm{a}$ & $\mathrm{p}_{x}+\mathrm{p}_{y}+\mathrm{p}_{z}-\mathrm{d}_{x z}+\mathrm{d}_{x y}+\mathrm{d}_{x}{ }^{2}-y^{2}$ & $\sigma$ & 1 & 10 & 0 & 14 \\
\hline
\end{tabular}

a $\alpha$-HOMO, $\alpha$-LUMO = 201, 202 MO; $\beta$-HOMO, $\beta$-LUMO = 200, 201 MO.

the $\alpha$-spin manifold. Other smaller contributions of $\alpha$ orbitals come from $\pi$ bonding interactions in 196a, 193a, and 191a MOs. Other minor contributions arise from interactions to the two empty $\beta \mathrm{e}_{\mathrm{g}}$ orbitals, and are mainly $\sigma$-type donor interactions in $184 \mathrm{~b}, 175 \mathrm{~b}, 169 \mathrm{~b}$, and 164b MOs.

The delocalization of $\alpha$ spin density from $\mathrm{O}(5)$ to $\mathrm{Mn}(1)$ can be associated with the overall increase of the $\mathrm{O}(5)-\mathrm{Mn}(1)$ bond order in going from R1 to Int1, which is mainly represented by the $\alpha$-spin $\mathrm{O}-\mathrm{Mn}$ bonding orbitals. From an energetic point of view, the extra bond strength acquired in this reaction step contributes to stabilize the system, relative to $\mathbf{R} \mathbf{1}$.

Transfer of $\beta$-spin density from $\mathrm{O}(6)$ to $\mathrm{O}(5)$ in the previous R1 to Int1 steps, left $\mathrm{O}(6)$ with excess alpha spin. This will prompt the approach to $\mathrm{O}(5)$, with transfer of $\alpha$-spin density, and $\mathrm{O}-\mathrm{O}$ bond formation. The excess of $\alpha$ spin accumulated in the previous reaction steps on $\mathrm{O}(6), \mathrm{O}(3)$ and $\mathrm{Mn}(1)$ find their way in the Int1-TS2-P1 reaction sequence to $\operatorname{Mn}(2)$ (Table 3 and Fig. 7). Basically, this sequence starts with spin transfer of $\sim 0.3$ spins from $\mathrm{O}-\mathrm{O}$ to the directly ligated $\mathrm{Mn}(1)$ in the Int1-TS2 step, followed by a net transfer of approximately 1.2 spins from several moieties to $\operatorname{Mn}(2)$ in the TS2-P1 step, distributed as $\sim 0.4$ spins coming from $\operatorname{Mn}(1), \sim 0.5$ from $\mathrm{O}(3)$, and $\sim 0.3$ from the $\mathrm{O}-\mathrm{O}$ pair. The preference for migration of the positive spin density to $\mathrm{Mn}(2)$ is consistent with the tendency of manganese in a weak field environment to adopt high spin states.

The most significant spin rearrangement in the Int1-TS2-P1 sequence occurs in the TS2-P1 step. According with the isodensity plots, the density is mostly modified around $\mathrm{O}(5), \mathrm{O}(6), \mathrm{Mn}(1), \mathrm{Mn}(2)$, and $\mathrm{O}(3)$, and to a lesser extent, around $\mathrm{O}(4)$, affecting oxygen orbitals of p symmetry, and orbitals of d symmetry around the manganese centers (Fig. 7). The spin density increases around $\mathrm{Mn}(2)$, and $\mathrm{O}(5)$, while it decreases around $\mathrm{O}(6), \mathrm{O}(4)$, and to a lesser extent around $\mathrm{O}(3)$. $\mathrm{Mn}(1)$ shows increase and decrease of spin density, with a net increase of spin, due to the Mn 3d orbitals participating in both the donor and acceptor MOs, and also due to induced polarization from $\operatorname{Mn}(2)$, via superexchange interactions. This spatial redistribution is consistent with a transition between the $\alpha$-HOMO (201a MO) and the $\alpha$-LUMO (202a MO) orbitals in TS2 (Fig. 10).

The exchange coupling constant $J=-300 \mathrm{~cm}^{-1}$ is indicative of moderately strong antiferromagnetic exchange among manganese centers [43]. Spin transfer to $\mathrm{Mn}(2)$ occurs from non-directly attached groups via several mechanisms. The effectiveness of the $\mathrm{Mn}(1) d$-based
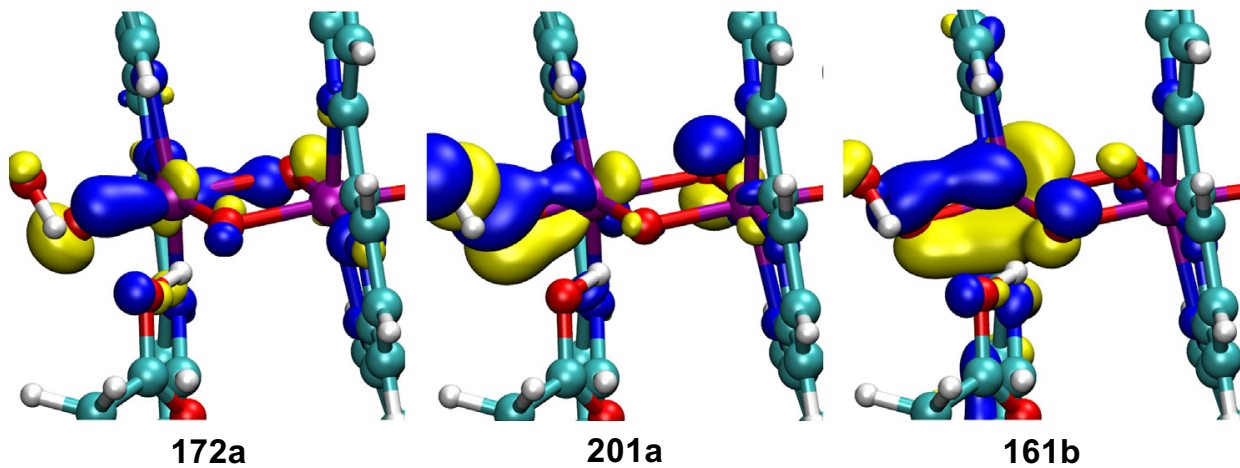

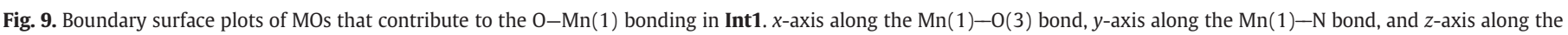
$\mathrm{Mn}(1)-\mathrm{O}(4)$ bond. 

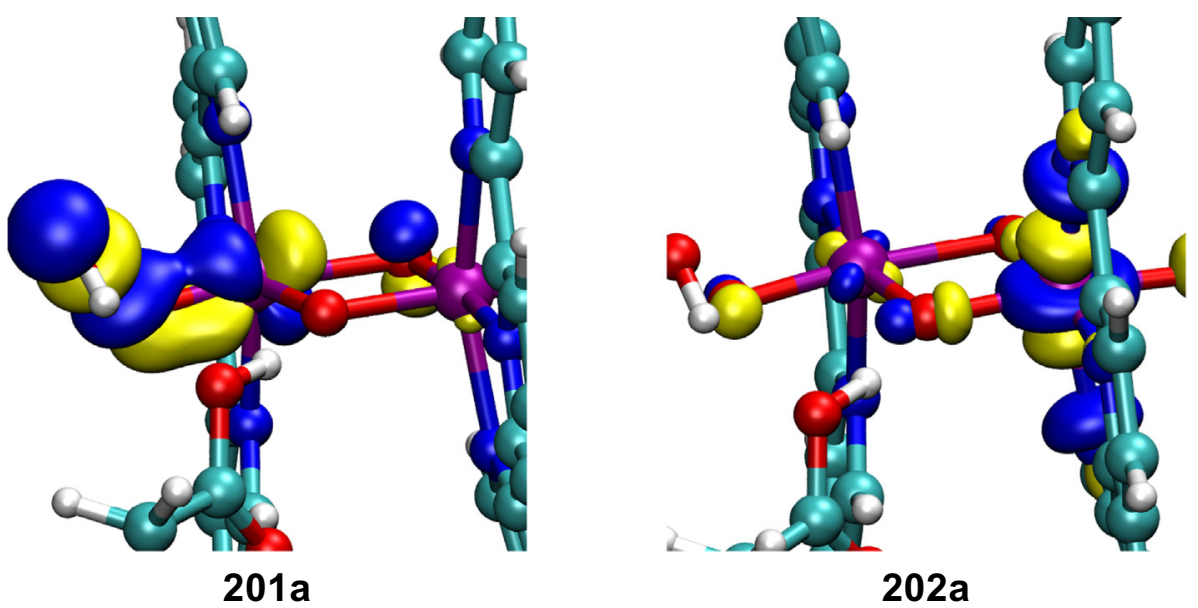

202a

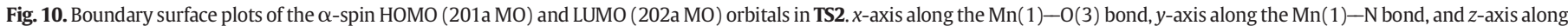
the $\mathrm{Mn}(1)-\mathrm{O}(4)$ bond.

MOs for superexchange is given by the extent of orbital contributions from the bridging oxide and the second manganese. Antiferromagnetic contributions to $J$ arise from delocalization of the excess spin-down electron density localized on $\mathrm{Mn}(1)$ onto $\mathrm{Mn}(2)$-centered $d$ orbitals whose spin-up counterparts are occupied. Inspection of the corresponding orbitals [92,93] (COs) in TS2 (Fig. 11) shows that the superexchange interaction is mediated through two $\pi$ pathways, $\operatorname{Mn}(1)\left(d_{y z}\right)-\mathrm{O}(4)\left(p_{z}\right)-\mathrm{Mn}(2)\left(d_{x z}\right) \quad(199 \mathrm{CO}, \quad \mathrm{S}=0.201)$, and $\operatorname{Mn}(1)\left(d_{x y}\right)-\mathrm{O}(3)\left(p_{z}\right)-\operatorname{Mn}(2)\left(d_{y z}\right)(200 \mathrm{CO}, \mathrm{S}=0.094)$, which involves oxygen $p$ orbitals perpendicular to the $\mathrm{Mn}_{2} \mathrm{O}_{2}$ plane.

$\pi^{*}$ orbitals of the hydroperoxo ligand (see Fig. S4 in SI) give the most important donor interactions with Mn d orbitals, and contribute to the $\mathrm{Mn}-\mathrm{OOH}$ bonding in the product $\mathbf{P 1}$. The in-plane $\pi_{\mathrm{h}}{ }^{*}$ alpha orbital of the hydroperoxo interacts with the $\mathrm{d}_{x z}$ orbital of $\mathrm{Mn}(1)$, via $\pi$ donation (Table 6). The resulting bonding orbital, $\pi_{\mathrm{h}}{ }^{*}+\mathrm{d}_{x z}, 196 \mathrm{a} \mathrm{MO}$, has $3 \%$ manganese and $20 \%$ hydroperoxo character, indicating a covalent $\pi$-donor bond [94]. The second $\pi^{*}$ orbital of the hydroperoxo (the outof-plane $\pi_{\mathrm{v}}{ }^{*}$ ) interacts with the $\mathrm{Mn} \mathrm{d}_{z}{ }^{2}$ to form a $\sigma$-type bonding $\pi_{\mathrm{v}}{ }^{*}+\mathrm{d}_{z}{ }^{2}$ orbital (199b MO) [95], which has $2 \%$ manganese and $58 \%$ hydroperoxo character (Fig. 12).

An additional bonding contribution within the alpha manifold comes from the out of plane $\pi_{\mathrm{v}}^{\mathrm{b}}$ orbital of the hydroperoxo, which interacts with the $\mathrm{d}_{x}{ }^{2}-y^{2}$ orbital of manganese, via $\pi$ donation. The resulting orbital $\pi_{\mathrm{v}}^{\mathrm{b}}-\mathrm{d}_{x}{ }^{2}-y^{2}$ contributes through two MOs, with $2 \%$ manganese and $24 \%$ hydroperoxo character in 150a MO, and $2 \%$ manganese and $18 \%$ hydroperoxo character in 151a MO. The 197a, 194a, 190a, and 169a have negligible contributions to bonding as they include bonding and antibonding interactions.

Within the beta manifold, there are also small contributions from $\sigma$-type donating orbitals from $\pi_{\mathrm{v}}{ }^{*}, \Pi_{\mathrm{v}}^{\mathrm{b}}$, and $\sigma^{\mathrm{b} *}$ hydroperoxo orbitals, through 199b, 150b, and 149b MOs, respectively.

The net effect is a bonding interaction, in which the $\pi^{*}$ orbitals of hydroperoxo are the most important contributors to bonding. These two orbitals are also responsible for binding in a mono Fe complex, but with significantly higher bonding strength contribution [96]. Among the several bonding contributions to $\mathrm{Mn}(1)-00,196 \mathrm{a} \mathrm{MO}$ is the most important, with 3\% metal admixture. The other interactions have $2 \%$ or less manganese contributions from 150a, 151a, and 199b MOs. Hence the $\mathrm{O}(5)-\mathrm{Mn}(1)$ bond strength is estimated to be smaller in P1 than R1.

\subsection{3. $R 2-T S 3-P 2$ reaction sequence}

PCET in going from $\mathbf{R} 2$ to TS3 reduces the $\beta$-spin HOMO-LUMO energy gap in $18.2 \mathrm{kcal} / \mathrm{mol}$. Direct examination of spin differences between

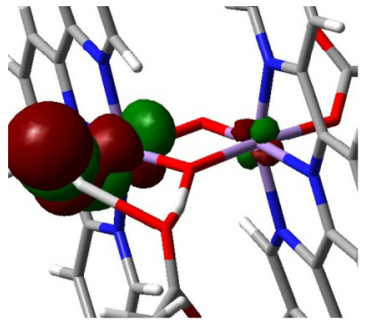

$198 \mathrm{a}$

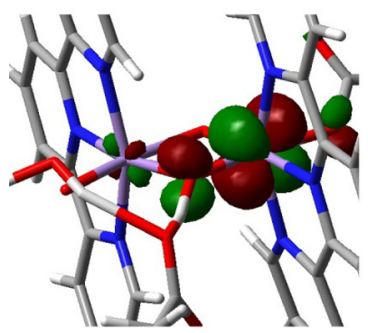

$199 a$

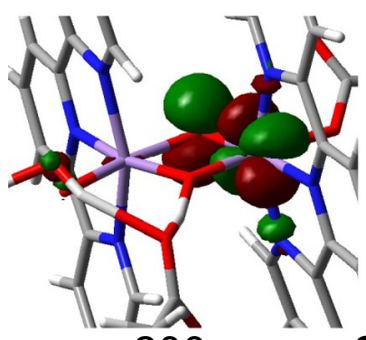

$200 a$

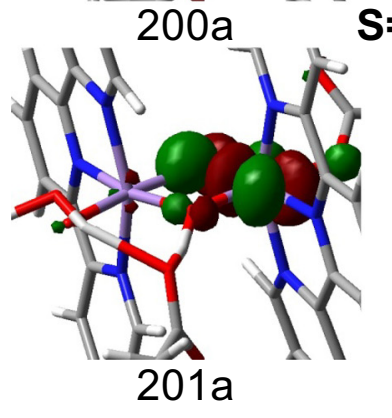

$S=0.201$

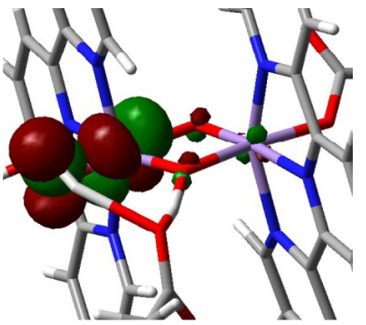

$198 b$
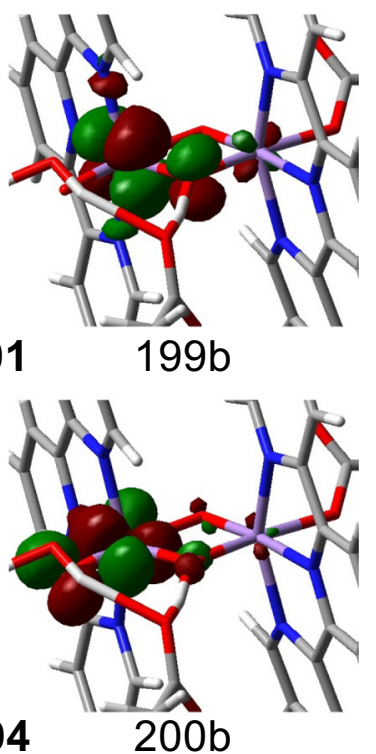

Fig. 11. Boundary surface plots of corresponding orbitals (COs) in TS2 
Table 6

Charge contributions of important MOs to the Mn(1)-O(oxide) bond in P1.

\begin{tabular}{|c|c|c|c|c|c|c|c|c|}
\hline \multirow[t]{2}{*}{$\mathrm{MO}^{\mathrm{a}}$} & \multirow[t]{2}{*}{ Orbital components (O-Mn) } & \multirow[t]{2}{*}{ Symmetry } & \multicolumn{2}{|l|}{$\operatorname{Mn}(1)$} & \multicolumn{2}{|c|}{$\mathrm{O}(5)$} & \multicolumn{2}{|c|}{$\mathrm{O}(6)$} \\
\hline & & & $s+p$ & $\mathrm{~d}$ & $\mathrm{~s}$ & $\mathrm{p}$ & $\mathrm{s}$ & $\mathrm{p}$ \\
\hline $199 b$ & $\pi_{\mathrm{v}}^{*}-\mathrm{d}_{z}^{2}+\mathrm{d}_{x}^{2}-y^{2}$ & $\sigma$ & 1 & $1\left(\mathrm{~d}_{x}^{2}-y^{2}\right), 1\left(\mathrm{~d}_{z}^{2}\right)$ & 0 & $25\left(p_{x}\right)$ & 0 & $20\left(p_{x}\right)$ \\
\hline $150 \mathrm{~b}$ & $\pi_{\mathrm{v}}^{\mathrm{b}}-\mathrm{d}_{x}^{2}-y^{2}$ & $\sigma$ & 0 & $2\left(\mathrm{~d}_{x}^{2}-y^{2}\right)$ & 0 & $2\left(\mathrm{p}_{\mathrm{x}}\right)$ & 0 & $3\left(\mathrm{p}_{\mathrm{x}}\right)$ \\
\hline $149 b$ & $\sigma^{\mathrm{b} *}-\mathrm{d}_{x}^{2}-y^{2}$ & $\sigma$ & 0 & $4\left(\mathrm{~d}_{x}^{2}-y^{2}\right)$ & 0 & $2\left(\mathrm{p}_{\mathrm{x}}\right)$ & 0 & $0\left(p_{x}\right)$ \\
\hline $197 a$ & $\pi_{\mathrm{h}}{ }^{*}-\mathrm{d}_{x z}+\mathrm{d}_{x y}$ & $\pi$ & 2 & 4 & 0 & 18 & 0 & 3 \\
\hline $196 a$ & $\pi_{\mathrm{h}}{ }^{*}-\mathrm{d}_{x z}$ & $\pi$ & 0 & 3 & 0 & 17 & 0 & 3 \\
\hline $194 a$ & $\pi_{\mathrm{v}}^{*}+\pi_{\mathrm{h}}{ }^{*}-\mathrm{d}_{x z}$ & $\pi$ & 0 & 3 & 0 & 8 & 0 & 3 \\
\hline $190 a$ & $\pi_{\mathrm{v}}{ }^{*}+\pi_{\mathrm{h}}{ }^{*}-\mathrm{d}_{x z} / \mathrm{d}_{x y}$ & $\pi$ & 1 & 11 & 0 & 10 & 0 & 2 \\
\hline $169 a$ & $\pi_{\mathrm{v}}^{\mathrm{b}}-\mathrm{d}_{z}^{2}$ & $\pi$ & 1 & 3 & 0 & 6 & 0 & 3 \\
\hline $151 \mathrm{a}$ & $\pi_{\mathrm{v}}^{\mathrm{b}}-\mathrm{d}_{x}^{2}-y^{2}$ & $\pi$ & 0 & 2 & 1 & 11 & 0 & 12 \\
\hline $150 a$ & $\pi_{\mathrm{v}}^{\mathrm{b}}-\mathrm{d}_{x}^{2}-y^{2}$ & $\pi$ & 1 & 2 & 0 & 9 & 0 & 9 \\
\hline
\end{tabular}

${ }^{\text {a }} \alpha-\mathrm{HOMO}, \alpha-\mathrm{LUMO}=201 \mathrm{a}, 202 \mathrm{a} \mathrm{MO} ; \beta-\mathrm{HOMO}, \beta-\mathrm{LUMO}=200 \mathrm{~b}, 201 \mathrm{~b}$ MO.

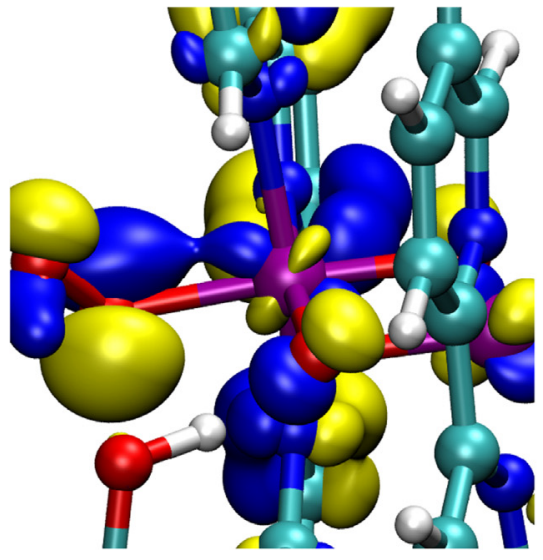

$196 a$

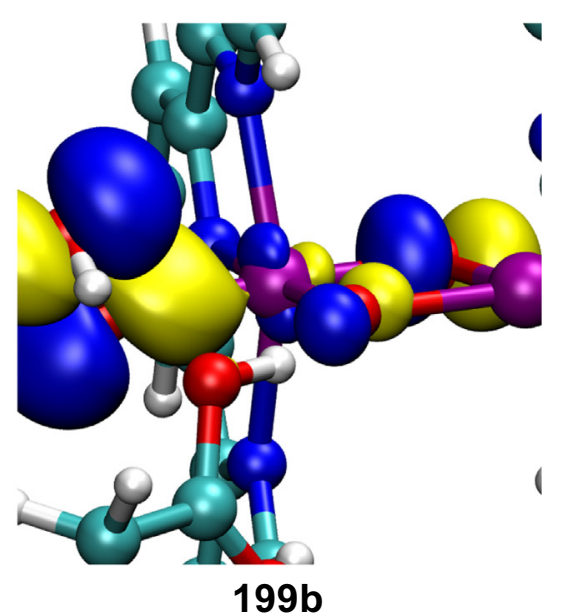

199b

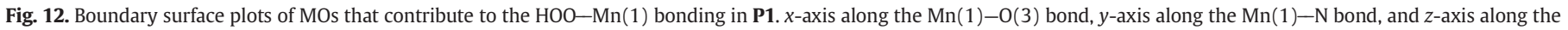
$\mathrm{Mn}(1)-\mathrm{O}(4)$ bond.

the $\mathbf{R} \mathbf{2}$ and TS3 shows a decrease of spin density of similar shape to the out-of-plane $\pi^{*}$ hydroperoxo orbital (the main component of the $\mathbf{R} 2 \beta-\mathrm{HOMO})$, and a density increase of the $\mathrm{Mn}(1) \mathrm{d}_{z}^{2}$, the main component of the $\mathbf{R} \mathbf{2} \beta$-LUMO (Figs. 13 and 14). This confirms that the reduction of the HOMO-LUMO gap facilitates the preconditions for electron transfer between these two moieties.

The most important contribution to the $\mathrm{Mn}(1)-\mathrm{OO}$ bonding in $\mathbf{R} \mathbf{3}$ (equivalent to P2) comes from the 180a MO, in which the $\pi_{\mathrm{v}}{ }^{*}$ orbital ${ }^{\dagger}$ from the $\mathrm{O}-\mathrm{O}$ superoxide (Section SI.6 in SI) radical interacts with Mn $\mathrm{d}_{x z}+\mathrm{d}_{y z}$ orbitals. 180a MO has 5\% manganese and 40\% superoxo character, indicating a covalent $\sigma$-donor bond (Table 7). Other contributions from the alpha manifold have $2 \%$ or less Mn contributions. Within the beta manifold, $183 \mathrm{~b}$ MO has a very high contribution of $\mathrm{d}_{z}^{2}(29 \%)$, but the covalency of the $\mathrm{Mn}(1)-00$ bond is very low, indicating that $\mathrm{d}_{z}^{2}$ is the $e_{g}$ filled orbital. The $\beta$-spin HOMO (184b MO) contributes to $\mathrm{Mn}-\mathrm{OO}$ bonding, which includes the in-plane $\pi_{\mathrm{h}}{ }^{*}$ orbital of the superoxo ligand that interacts with the $\mathrm{d}_{x}{ }^{2}-y^{2}$ and $\mathrm{d}_{z}{ }^{2}$ orbitals of $\mathrm{Mn}(1)$, in a $\sigma$-type bonding interaction. 184b MO has $2.1 \% \mathrm{~d}_{x}{ }^{2}-y^{2}$, and $1.3 \% \mathrm{~d}_{z}^{2}$ contributions, and $21 \% \mathrm{p}_{\mathrm{x}}$ superoxo character, indicating a covalent $\sigma$-donor bond (Table 7 ). $137 \mathrm{~b}$ MO has only $1 \%$ Mn contribution. No other significant contribution from the beta manifold is observed.

The bond strength in this case has only one significant contribution from the $180 \mathrm{a} \mathrm{MO}$, with $5 \%$ manganese. This indicates that the bond

† The v ("vertical") subscript is relative to this particular arrangement, and indicates the orbital lobes are perpendicular to the $0-0-\mathrm{Mn}(1)$ plane. Concomitantly, the $\mathrm{h}$ ("horizontal") subscript indicates the orbitals lobes are parallel to the mentioned plane. strength is weaker than $\mathbf{P 1}$, which clearly gets the ligand ready to be cleaved in the following step.

\subsubsection{R3-TS4-Int2-TS34/43-P3 reaction sequence}

The major spin rearrangement within this sequence occurs between the Int2 and TS34 steps, in which there is spin transfer between $\mathrm{O}-\mathrm{O}$ and $\mathrm{Mn}(1)$. Spin density isosurfaces show that the involved orbitals have $\pi$ symmetry in the region of $\mathrm{O}-\mathrm{O}\left(\pi^{*}(\mathrm{OO})\right)$, and d symmetry in the $\mu-\mathrm{O}$ plane around $\mathrm{Mn}(1)$ (Fig. 15). The region around $\mathrm{Mn}(2)$ shows redistribution of spin, without net change.

The $0-0$ superoxide radical ligand in Int 2 has a $\pi^{*}$ orbital $(200 \mathrm{~b}$ $\mathrm{MO}$, the $\beta$-spin HOMO) that has donor interactions with Mn d orbitals and contributes to the $\mathrm{Mn}-\mathrm{OO}$ bonding. The in-plane $\pi_{\mathrm{h}}{ }^{*}$ orbital of the superoxo ligand interacts with the $\mathrm{d}_{x}{ }^{2}-y^{2}$ orbital of $\mathrm{Mn}(1)$, resulting in a $\sigma$-type bonding molecular orbital $\pi_{\mathrm{h}}{ }^{*}+\mathrm{d}_{x}{ }^{2}-y^{2}$ (Fig. 16). This component of 200b MO has $7 \% \mathrm{~d}_{x}{ }^{2}-y^{2}$ and $55 \%$ superoxo character from the $\mathrm{p}_{\mathrm{x}}$ orbitals, indicating a covalent $\sigma$-donor bond. There are additional small contributions to 00-Mn(1) bonding from 200a, 194a, and 192a MOs (Table 8).

Electron transfer initiates with HOMO-LUMO transition. The $\beta$-spin LUMO (201b MO) is formed by the antibonding combination $\pi_{\mathrm{h}}{ }^{*}(\mathrm{OO})-\mathrm{d}_{x}{ }^{2}-y^{2}(\mathrm{Mn}(1)$ orbital; while, the $\beta$-spin HOMO (201b MO) is the main contributor to the OO-Mn(1) bond. The HOMO-LUMO transition therefore facilitates charge transfer from the $\mathrm{OO}-\mathrm{Mn}(1)$ bond to the $\mathrm{Mn}$ center. In this way, electron transfer assists $\mathrm{OO}-\mathrm{Mn}(1)$ bond cleavage, by weakening the metal ligand bond strength. From a spatial perspective, both donor and acceptor MOs are partially localized on 

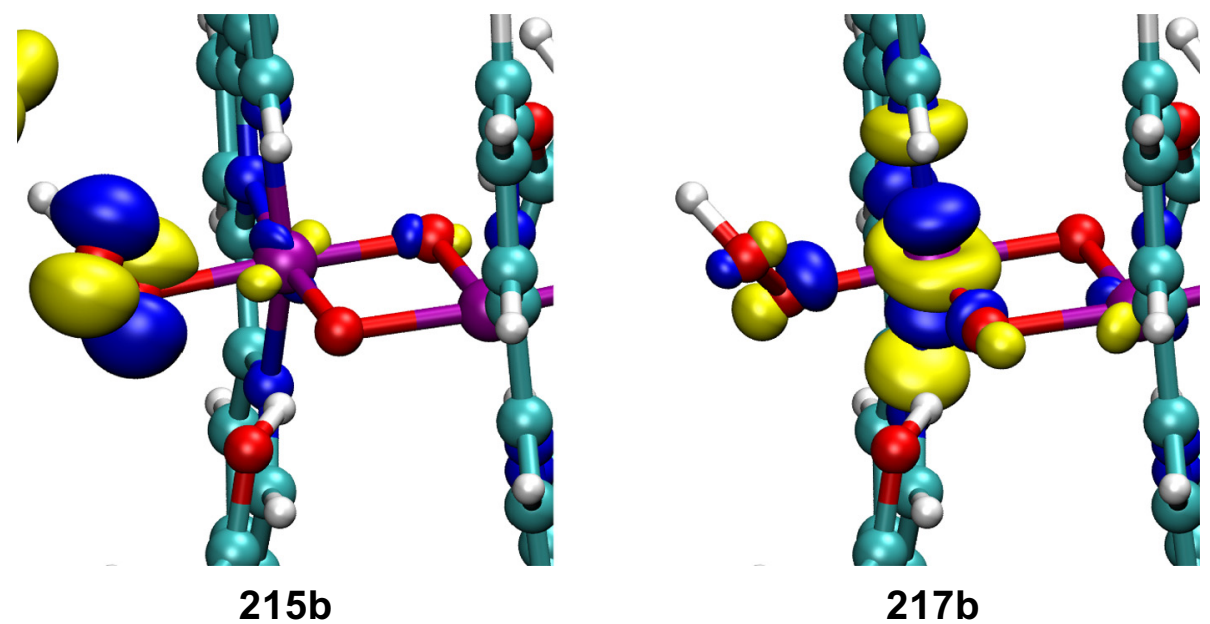

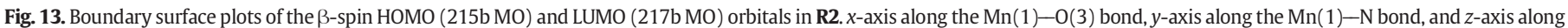
the $\mathrm{Mn}(1)-\mathrm{O}(4)$ bond.

$\mathrm{O}-\mathrm{O}$ and $\mathrm{Mn}(1)$, which facilitates electron transfer. Release of the $\mathrm{O}-\mathrm{O}$ moiety in the last reaction step gives room to the return of another water ligand during the following catalytic cycle.

A comparison between configurations with the $\mathrm{AcOOH}$ hydrogen bonded and not hydrogen bonded to $\mu-\mathrm{O}$ in $\mathbf{R} \mathbf{3}$, shows there is an increase of the contribution of the $\beta$-spin HOMO $\mathrm{d}_{x}{ }^{2}-y^{2}$ component from $2 \%$ to $3 \%$ in going from the non-bonded to the hydrogen bonded configuration, and this contribution increases even further when the proton is transferred from AcOOH to $\mu-\mathrm{O}$ ( $7 \%$ of $\mathrm{d}_{x}{ }^{2}-y^{2}$, see Table 9 ). Along the same series, the $\mathrm{p}_{x}$ component decreases from $21 \%$, to $20 \%$, to $17 \%$, respectively. This tendency shows charge shift from the ligand to the metal, which will facilitate the reduction of $\mathrm{Mn}(1)$. This suggests that the catalyst takes advantage of proton donor groups coordinated to the oxo bridge ligands, to facilitate $\mathrm{OO}-\mathrm{Mn}$ bond rupture, and $\mathrm{Mn}$ reduction via a fine-tuned HOMO-LUMO transition.

\section{Discussion}

As the reaction advances, the approaching water oxido ligand combination in $\mathbf{R} 1$ evolves to hydroperoxo in P1, to superoxo in P2, and finally diooxygen in $\mathbf{P 3}$, with oxygen formal oxidation states associated with the $(0,0)$ pair increasing from $(-2,-1)$ to $(-1,-1)$, $(-1 / 2,-1 / 2)$ and $(0,0)$, respectively. In all these steps, the redox

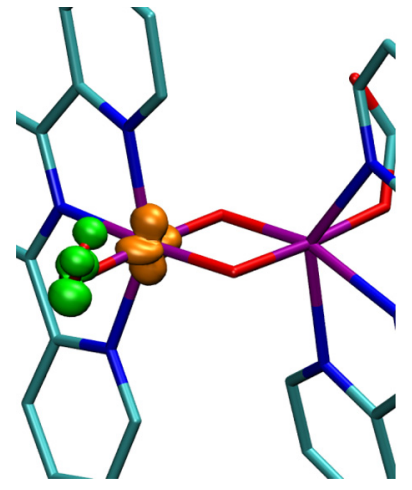

R2 to TS3

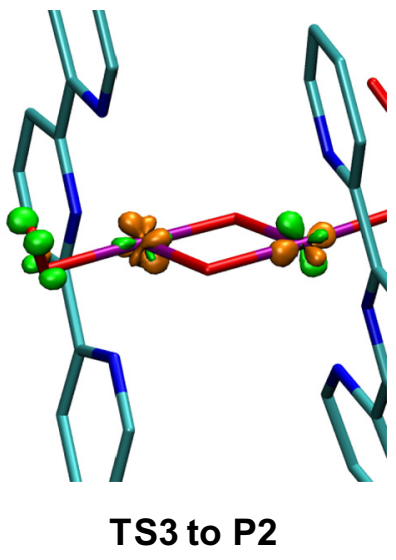

TS3 to P2
Fig. 14. Spin density differences at different stages of the hydroperoxo to superoxo ion formation reaction sequence. The densities at different configurations are obtained via subtraction of the last state minus the previous state. Green isosurfaces correspond to more positive spin with respect to the initial state, while orange isosurfaces correspond to a decrease of spin density. partner is manganese. In the first step, there is $\beta$-spin transfer from $\mathrm{O}(6)$ to $\mathrm{O}(5)$, which compensates the initial excess alpha spin on $\mathrm{O}(5)$, and prepares for the $\mathrm{O}-\mathrm{O}$ singlet bond formation. The following spin transfer occurs from the $\mathrm{O}-\mathrm{O}$ system to the outer-most $\mathrm{Mn}(2)$ center. The last two oxidation steps include spin transfer from the $\mathrm{O}-\mathrm{O}$ to the directly attached $\mathrm{Mn}(1)$. In each step there is reduction of the $\mathrm{OO}-\mathrm{Mn}(1)$ binding strength, with concomitant increase of the $\mathrm{O}-\mathrm{O}$ bond strength, which culminates with the release of $\mathrm{O}_{2}$ in the last step. The HOMO in the last step is localized in the $00-\mathrm{Mn}(1)$ bond, which means that charge transfer contributes directly to $00-\mathrm{Mn}(1)$ bond cleavage. This last step is entropy driven, while formation of hydroperoxide and superoxide moieties is enthalpy driven.

Along the reaction, the spin density associated with the $\mathrm{O}-\mathrm{O}$ pair takes the approximate values (rounded to the nearest integer) $1,0,1$, and 2 spins. Only the first transition is alpha transfer, while the other two are beta spin transfers. Spin transfer in the steps $\mathbf{R} \mathbf{2}$ to $\mathbf{P} \mathbf{3}$ is required to increase the number of unpaired electrons of the $\mathrm{O}-\mathrm{O}$ bond, as well as weakening of the $00-\mathrm{Mn}(1)$ bond, which ultimately will allow the entropy-driven release of $\mathrm{O}_{2}$. Beta spin transfer from $\mathrm{OO}$ is more efficient as it involves the adjacent nucleus $\mathrm{Mn}(1)$, and is observed in most of the reaction steps.

The first step (R1 to $\mathbf{P 1}$ ) requires spin transfer of the opposite spin (alpha) to aid in the $\mathrm{O}-\mathrm{O}$ bond formation, which requires both alpha and beta spin rearrangements within the $\mathrm{OO}$ moiety to form the $\mathrm{O}-\mathrm{O}$ bond. Alpha spin transfer also assists in keeping closer the oxidation states of both metal centers. The weak field manganese ligands create a small $t_{2 g}-e_{g}$ gap, making the high spin state the most stable. The transfer of spin to the outermost manganese center in the $\mathrm{O}-\mathrm{O}$ formation is therefore to conserve the manganese high spin state.

The strength of the hydrogen bond between $\mathrm{AcOOH}$ and the $\mu-\mathrm{O}$ bridging ligands also increases along the reaction path, with proton

Table 7

Charge contributions of important MOs to the $\mathrm{Mn}(1)-\mathrm{OO}$ (superoxo) bond in $\mathbf{R}$.

\begin{tabular}{|c|c|c|c|c|c|c|c|c|}
\hline \multirow[t]{2}{*}{$\mathrm{MO}^{\mathrm{a}}$} & \multirow{2}{*}{$\begin{array}{l}\text { Orbital components } \\
\text { (O-Mn) }\end{array}$} & \multirow[t]{2}{*}{ Symmetry } & \multicolumn{2}{|l|}{$\operatorname{Mn}(1)$} & \multicolumn{2}{|c|}{$\mathrm{O}(5)$} & \multicolumn{2}{|c|}{$\mathrm{O}(6)$} \\
\hline & & & $s+p$ & d & $\mathrm{s}$ & $\mathrm{p}$ & $\mathrm{s}$ & $\mathrm{p}$ \\
\hline $184 b$ & $\pi_{\mathrm{h}}{ }^{*}-\mathrm{d}_{x}^{2}-y^{2}+\mathrm{d}_{z}^{2}$ & $\sigma$ & 1 & 3.5 & 0 & $21\left(p_{x}\right)$ & 0 & $41\left(p_{x}\right)$ \\
\hline $183 b$ & $\pi_{\mathrm{h}}^{*}-\hat{\mathrm{d}}_{\mathrm{z}}^{2}$ & $\sigma$ & 2 & 29 & 0 & $0.4\left(p_{x}\right)$ & 0 & $4\left(\mathrm{p}_{x}\right)$ \\
\hline $137 b$ & $\pi_{\mathrm{h}}^{\mathrm{b}}-\mathrm{d}_{x}^{2}-y^{2}$ & $\sigma$ & 1 & 1 & 1 & $11\left(\mathrm{p}_{x}\right)$ & 0 & $12\left(\mathrm{p}_{x}\right)$ \\
\hline $183 a$ & $\pi_{\mathrm{v}}^{*}-\mathrm{d}_{y z}$ & $\pi$ & 0 & 2 & 0 & 18 & 0 & 19 \\
\hline $180 \mathrm{a}$ & $\pi_{\mathrm{v}}^{*}-\mathrm{d}_{x z}+\mathrm{d}_{y z}$ & $\pi$ & 0 & 5 & 0 & 18 & 0 & 22 \\
\hline $137 a$ & $\pi_{\mathrm{h}}^{\mathrm{b}}-\mathrm{d}_{z}^{2}+\mathrm{d}_{x}^{2}-y^{2}$ & $\sigma$ & 1 & 1 & 2 & 38 & 1 & 25 \\
\hline $126 a$ & $\pi_{v}^{\mathrm{b}}-\mathrm{d}_{x z}$ & $\pi$ & 2 & 1 & 0 & 31 & 0 & 26 \\
\hline $116 a$ & $\sigma^{\mathrm{b}}-\mathrm{d}_{x y}+\mathrm{d}_{x}^{2}-y^{2}$ & $\sigma, \pi$ & 2 & 1 & 0 & 11 & 2 & 10 \\
\hline
\end{tabular}

a $\alpha$-HOMO, $\alpha$-LUMO $=185 \mathrm{a}, 186 \mathrm{a}$ MO, $\beta$-HOMO, $\beta$-LUMO $=184 \mathrm{~b}, 185 \mathrm{~b}$ MO. 


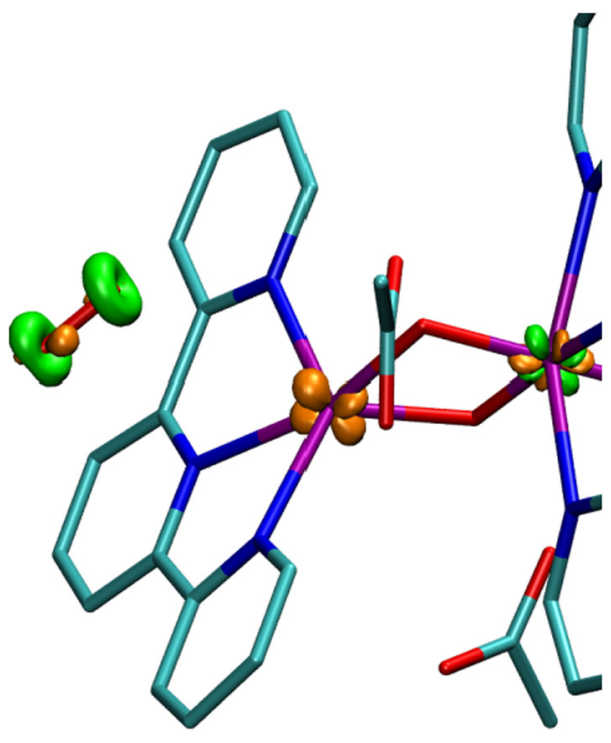

Int2 to TS34

Fig. 15. Spin density differences at the Int 2 to TS34 step of the superoxo to paramagnetic di-oxygen formation reaction sequence. The densities at different configurations are obtained via subtraction of the last state minus the previous state. Green isosurfaces correspond to more positive spin with respect to the initial state, while orange isosurfaces correspond to a decrease of spin density.

transfer to the $\mu-\mathrm{O}$ ligands in the last $\mathrm{Mn}^{\mathrm{II}}-\mathrm{Mn}^{\mathrm{III}}$ step. This property is correlated with charge transfer from the $\mathrm{OO}-\mathrm{Mn}$ bond to $\mathrm{Mn}$, facilitating the $\mathrm{OO}-\mathrm{Mn}$ bond rupture, and reduction of $\mathrm{Mn}$, via $\mathrm{HOMO}-$ LUMO interactions.

One of the findings of this investigation is that in the initial state R1, the oxygen ligand has an intermediate spin between zero (non radical) and one (oxyl radical). From a methodological point of view, it suggests that broken symmetry DFT, and particularly the inclusion of solvent in the calculations gives a particularly realistic description of the experimental process.

From a mechanistic perspective, the attacking water molecule plays an active role in the $\mathrm{O}-\mathrm{O}$ formation (beyond being merely attracted by the oxido ligand). It requires to be properly oriented and retained in place, to proceed with the $\mathrm{O}-\mathrm{O}$ bond formation reaction. Also, it
Table 8

Charge contributions of important MOs to the $\mathrm{Mn}(1)-\mathrm{OO}$ (superoxide) bond in Int2

\begin{tabular}{|c|c|c|c|c|c|c|c|c|}
\hline \multirow[t]{2}{*}{$\mathrm{MO}^{\mathrm{a}}$} & \multirow{2}{*}{$\begin{array}{l}\text { Orbital components } \\
\text { (O-Mn) }\end{array}$} & \multirow[t]{2}{*}{ Symmetry } & \multicolumn{2}{|l|}{$\operatorname{Mn}(1)$} & \multicolumn{2}{|c|}{$\mathrm{O}(5)$} & \multicolumn{2}{|c|}{$\mathrm{O}(6)$} \\
\hline & & & $s+p$ & d & $\mathrm{s}$ & $\mathrm{p}$ & $\mathrm{s}$ & $\mathrm{p}$ \\
\hline $200 \mathrm{~b}$ & $\pi_{\mathrm{h}}^{*}-\mathrm{d}_{x}^{2}-y^{2}$ & $\sigma / \mathrm{B}$ & 0 & 7 & 0 & $17\left(\mathrm{p}_{x}\right)$ & 0 & $38\left(p_{x}\right)$ \\
\hline $200 a$ & $\pi_{\mathrm{h}}^{*}-\mathrm{d}_{x y}+\mathrm{d}_{x}^{2}-y^{2}$ & $\pi / B$ & 0 & 1 & 0 & 13 & 0 & 20 \\
\hline $194 a$ & $\pi_{\mathrm{v}}^{*}-\mathrm{d}_{x z}$ & $\pi / B$ & 1 & 3 & 0 & 6 & 0 & 6 \\
\hline $192 a$ & $\pi_{\mathrm{v}}^{*}-\mathrm{d}_{x z}$ & $\pi / B$ & 0 & 3 & 0 & 26 & 0 & 31 \\
\hline
\end{tabular}

a $\alpha$-spin HOMO, LUMO: 201a, 202a MO; $\beta$-spin HOMO, LUMO: 200b, 201b MO.

presents electrophilic properties, in addition to those present in the water molecule ligated to Mn. From a PSII perspective, this suggests that positioning of the attacking water molecule is a key step, and that the electrophilic properties may not be only present in the water molecule ligated to Mn, but also on the attacking water molecule.

Although the $\mu-O$ ligands were proposed as reactants in some models of the OEC of PSII [37,97,98], the results of the present report suggest that the oxo bridging ligands do not act as reactants. We found that the oxo-bridging ligands have the following functions and characteristics along the reaction:

1) provision of the appropriate strength to the ligand metal field in different reaction steps,

2) anchor molecular species, such as AcOOH. This species aids in the positioning of reactive groups, particularly the orientation and positioning of the attacking water molecule at the beginning of the reaction,

3) hold p-orbitals that provide support for super-exchange spin interaction pathways.

4) bind protons that stabilize manganese in low oxidation states,

5) assistance in charge shifting from the $\mathrm{OO}-\mathrm{Mn}$ bond to $\mathrm{Mn}$ in the last reaction step (after $\mu-\mathrm{O}$ protonation), which contributes to $\mathrm{OO}-\mathrm{Mn}$ cleavage via HOMO-LUMO interactions.

Energy differences between intermediates and transition states during proton transfers to $\mathrm{AcOO}^{-}$are very small $(\leq 1 \mathrm{kcal} / \mathrm{mol}$, usually within the error of the DFT methodology). This is due to $\mathrm{AcOO}^{-}$is a very good base (e.g., $\mathrm{pK}_{\mathrm{b}}=9.25$ in $\mathrm{CH}_{3} \mathrm{COONa}$ ), and hence these steps are basically barrier-less.

Barriers along the catalytic reaction of water oxidation analyzed in the preceding sections are always lower than the 19-21 kcal/mol experimental value. However, according with the experimental results, the rate-limiting step is the formation of the highest oxidized species

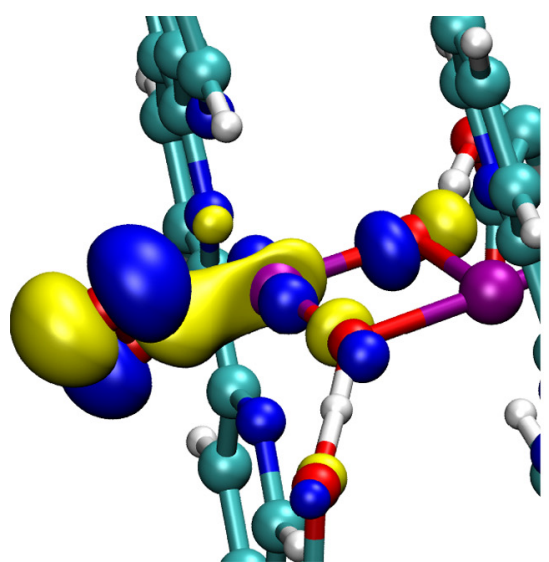

$200 b$

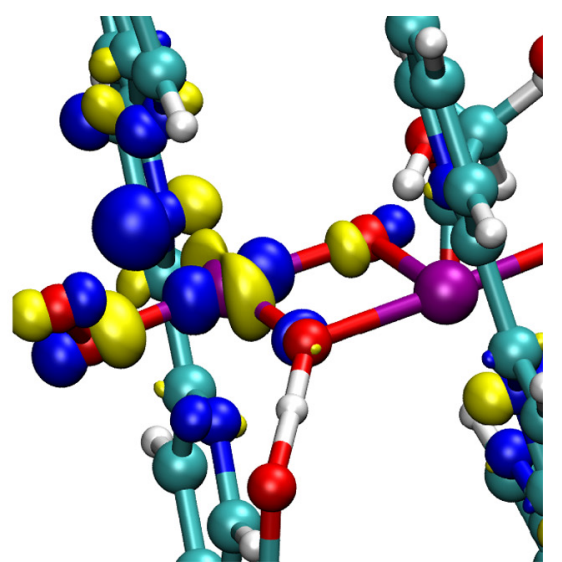

201b

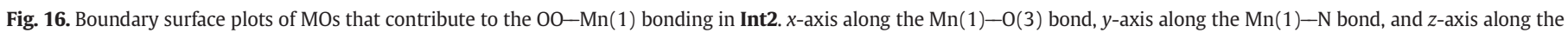
$\mathrm{Mn}(1)-\mathrm{O}(4)$ bond. 
Table 9

$\mathrm{Mn}(1) 3 \mathrm{~d}$, and $\mathrm{O}$ (5) 2p components of the $\beta$-spin HOMO in R3 (Mn oxidation state $\mathrm{Mn}(\mathrm{III}, \mathrm{III})$ ) for several $\mathrm{AcOOH}-\mathrm{O}(4)$ bonding modes.

\begin{tabular}{lllll}
\hline \multirow{2}{*}{ Center } & Orbital & \multicolumn{3}{l}{$\mathrm{H}-\mathrm{O}(4)$ bond type } \\
\cline { 3 - 5 } & & No bond & H-bond & Covalent bond \\
\hline \multirow{3}{*}{ Mn(1) } & $\mathrm{d}_{z}{ }^{2}$ & 1 & 1 & 0 \\
& $\mathrm{~d}_{x z}$ & 0 & 0 & 0 \\
& $\mathrm{~d}_{y z}$ & 4 & 4 & 3 \\
& $\mathrm{~d}_{x}{ }^{2}-{ }^{2}$ & 2 & 3 & 7 \\
$\mathrm{O}(5)$ & $\mathrm{d}_{x y}$ & 0 & 0 & 0 \\
& $\mathrm{p}_{x}$ & 21 & 20 & 17 \\
& $\mathrm{p}_{y}$ & 5 & 4 & 3 \\
& $\mathrm{p}_{z}$ & 1 & 2 & 2 \\
\hline
\end{tabular}

(R1 in our nomenclature) by oxidation of $\operatorname{Mn}(1)^{\mathrm{IV}}-\mathrm{Mn}(2)^{\mathrm{III}}[6,50]$, or peroxymonosulfate binding [63], both of which occur prior to the $\mathrm{O}-\mathrm{O}$ formation. Hence, the fact that the $\mathrm{O}-\mathrm{O}$ bond formation and dioxygen $\mathrm{O}_{2}$ evolution reaction does not include the rate-limiting step, support the experimental findings.

Water splitting catalyzed by $\mathbf{1}$ is a paradigm for PSII. It oxidizes bulk water to give molecular dioxygen. The whole process relies in several key factors.

1) the presence of a strong base $\left(\mathrm{AcOO}^{-}\right)$, which acts as a proton abstractor in all proton transfer processes;

2) the availability of at least two metal centers to interchange spin and act as redox partners of the 00 moiety;

3 ) the accessibility of nearby groups to help accommodate/orient the reactant species, as well as provide protons necessary to achieve a low metal oxidation state $\left(\mathrm{Mn}^{\mathrm{II}}-\mathrm{Mn}^{\mathrm{III}}\right)$. This role is also performed by solution $\mathrm{AcOOH}$.

The role of $\mathrm{AcOO}^{-}$is remarkable, as $\mathrm{AcOO}^{-}$is not an integral part of the catalyst, and only belongs to the solution buffer. The parallelism with PSII is compelling, as the natural system also requires a proton acceptor group to trap the exiting protons from the water splitting reaction. This role can be played by either D1-Asp170, or O5 (the $\mu-\mathrm{O}$ bridging ligand between $\mathrm{Mn}(3)$ and $\mathrm{Mn}(4)$ in the $\mathrm{OEC}$ ), according with current X-ray models [37].

Proposals for the mechanism of $\mathrm{O}-\mathrm{O}$ bond formation in PSII can be grouped into two major categories based on the nature of the bound substrate water molecules. The first group involves coupling reactions of an oxyl radical [34,99-101]. The second category of mechanisms for water oxidation involve nucleophilic attack of a calcium-bound water (or hydroxide) ligand on the electrophilic oxygen atom of an $\mathrm{Mn}^{\mathrm{V}}=0$ intermediate in the $\mathrm{O}-\mathrm{O}$ bond-forming step [55,102-104]. The finding of a partial oxidation state, with a magnitude intermediate between an oxyl radical $\left(\mathrm{Mn}^{\mathrm{IV}}-\mathrm{O}^{\mathrm{I}}\right)$ and an oxo ligand $\left(\mathrm{Mn}^{\mathrm{V}}=\mathrm{O}\right)$ in the $\mathbf{R} \mathbf{1}$ state of the reaction catalyzed by $\mathbf{1}$ may reconcile the two most accepted proposals for the mechanism of $\mathrm{O}-\mathrm{O}$ bond formation in PSII. Gupta et al. also present an intermediate alternative, by providing spectroscopic evidence for $\mathrm{O}$ radical character in a complex containing a formal $\mathrm{Mn}(\mathrm{V})$ ion [105-107].

After the $\mathrm{S}_{3}$ state of the PSII Kok cycle, several spectroscopic studies, including time-resolved ultraviolet-visible [108,109], electron paramagnetic resonance [110], infrared spectroscopy [111], Mn K-edge XAS [112], and femtosecond X-ray diffraction [113], suggest the presence of a transient state $S_{3} Y_{Z}^{O X}$, also referred to as $S_{3}{ }^{\prime}[109,111]$. This intermediate state hints to deprotonation occurs prior to the onset of $\mathrm{Mn}$ redox chemistry. One of the reasons of the delay in starting the $\mathrm{Mn}$ redox chemistry in going from $\mathrm{S}_{3}$ to $\mathrm{S}_{4}$ in PSII was postulated to be the restructuration of the hydrogen bond network [109]. In line with this findings, after $\mathrm{O}(5)$ in $\mathbf{1}$ is oxidized in $\mathbf{R} \mathbf{1}$, a delay may occur due to reprotonation of the $\mathrm{AcCOOH}$ directed ligated to the reactant water molecule, or due to substitution with a protonated acetate in the second solvation shell.
Although Rivalta et al. discuss the same catalyst in a similar experimental setup [62]; there are differences with the catalytic process explained in this investigation:

1) O-O bond formation ( $\mathbf{R} 1$ to $\mathbf{P 1}$ ): We showed a systematic analysis showing that $\mathrm{AcOH}$ is hydrogen bonded to the oxo bridge ligands. This poise a difference on where the substrate water anchors during the first step of the reaction. In our case, it is the oxygen of the $\mathrm{AcOH}$ $\mathrm{H}$-bonded to the oxo-bridge ligand, whereas Rivalta et al. proposes an oxo-bridge ligand. There is consistency in both investigations that bulk acetate is the base that captures the leaving proton. The spin rearrangement is similar in both investigations.

2) Formation of superoxide ( $\mathbf{R 2}$ to $\mathbf{P 2}$ ): In our case there is proton transfer from the hydroperoxo to a bulk acetate and electron transfer from the hydroperoxo to the adjacent $\mathrm{Mn}(1)$; whereas in Rivalta et al. the proton transfer is to an oxo bridge ligand, with electron transfer from the $\mathrm{HOO}$ to the adjacent $\mathrm{Mn}(1)$. As a result, the bridge is protonated in their model, at difference with our model.

3) Molecular di-oxygen formation $\left({ }^{3} \mathrm{O}_{2}\right)$ ( $\mathbf{R} 3$ to $\left.\mathbf{P 3}\right)$ : In our case there is proton transfer from the two $\mathrm{H}$-bonded acetates to the oxo bridges, and electron transfer from the superoxo to the adjacent $\mathrm{Mn}(1)$; whereas in Rivalta et al. there is only one proton transfer, which is from bulk acetate to the unprotonated oxo bridge.

4) The methodology is also different, with different basis sets (ours is larger), and different ways of including the solvent in the calculations. In particular, our optimizations in solvent are closer to the experimental conditions.

Early works of Lundberg et al. also addressed the mechanisms of the reaction catalyzed by $\mathbf{1}[59,66]$. In these studies only the $\mathrm{O}-\mathrm{O}$ bond formation step was analyzed (R1 to P1). There is no acetate involved in the reaction, i.e., the base capturing protons is one of the oxo-bridge ligands, instead of acetate in our approach. The spin transfer is also different than in our approach, i.e., the spin from the HOO moiety in the last step of the $\mathbf{R} 1$ to $\mathbf{P 1}$ sequence is transferred to the directly attached $\mathrm{Mn}(1)$ center in the Lundberg et al. model, whereas the transfer is to the outermost $\mathrm{Mn}(2)$ in our approach. This different spin rearrangement lowers the barrier in this step.

\section{Summary and Conclusions}

In summary, we have shown that the terpy complex (1) catalyzes the oxidation of water to give oxygen, with a process that signals several possible similarities with the equivalent process in PSII. The model includes high spin manganese centers in the III and IV oxidation sates in a $\mu$-oxo bridge arrangement, and a partial oxido radical, as reactants. This radical becomes an electrophile, and reacts with a bulk water molecule. We proposed a mechanism in which the manganese center not directly attached to the reactant oxido species is not a simple spectator, but a key factor in the $\mathrm{O}-\mathrm{O}$ bond formation reaction. It participates in spin density transfer during the $\mathrm{O}-\mathrm{O}$ bond formation reaction. In consistency with the $\mathrm{OEC}$, in which proton acceptor groups are implicated in trapping the exiting protons from the water splitting reaction, the reaction catalyzed by 1 uses the $\mathrm{AcOO}^{-}$base from the buffer solution as proton receptor, which makes the reaction less energetically stringent than oxo bridge ligands as proton acceptors.

The rate-limiting step does not belong to the molecular paramagnetic dioxygen formation reaction, concomitant with experimental findings in which the rate-limiting step is the oxidation of $\mathrm{Mn}$ (IV,III) to the formal $\mathrm{Mn}(\mathrm{IV}, \mathrm{V})$ oxidation state. Our findings establish that there is unpaired spin density associated with the oxido ligand in $\mathrm{O}-\mathrm{Mn}(1)$, at the beginning of the $\mathrm{O}-\mathrm{O}$ bond formation reaction, yet the density is less than what is expected for an oxyl radical. This result suggests the possibility that a high-spin $\mathrm{Mn}^{\mathrm{V}}$-oxo center could be operative within the $\mathrm{S}_{4}$ state of the OEC. This might be a remarkable property, as despite the suggestion that $\mathrm{Mn}^{\mathrm{V}}$ may be a key component 
of S4, presently there are no crystallographically characterized small molecule complexes containing $\mathrm{Mn}^{\mathrm{V}}$ as dinuclear or higher nuclearity structures [8].

\section{Acknowledgment}

The author thanks the support of the Department of Chemistry \& Biochemistry, University of the Sciences in Philadelphia, and support from the National Science Foundation (NSF CHE-1229564 and MSN-1049771). This work used the Extreme Science and Engineering Discovery Environment (XSEDE), which is supported by National Science Foundation grant number OCI-1053575, and the XSEDE Science Gateways Program.

\section{Appendix A. Supplementary data}

Methodology used to include the solvent in the calculations; arrangement of $\mathrm{H}_{2} \mathrm{O}$ hydrogen bonded to the $\mu-\mathrm{O}(3)$ ligand instead of $\mathrm{AcOOH}$ with $\mathrm{Mn}$ oxidation state $\mathrm{Mn}(\mathrm{IV}, \mathrm{IV})$; configuration corresponding to alternate mechanism of proton transfer to $\mu-\mathrm{O}(4)$ ligand in the $\mathrm{O}-\mathrm{O}$ bond formation step; comparison of different levels of theory of calculated free energies along the reaction pathway; description of spin redistribution along the $\mathrm{O}-\mathrm{O}$ bond formation step in the R1-P1 reaction sequence; electronic structure of the hydroperoxo and superoxo ion ligands. This material is available free of charge via the Internet. Supplementary data associated with this article can be found in the online version, at http://dx.doi.org/10.1016/j.jinorgbio.2017.02.014.

\section{References}

[1] P. Joliot, G. Barbieri, R. Chabaud, Photochem. Photobiol. 10 (1969) 309-\&.

[2] B. Kok, B. Forbush, M. McGloin, Photochem. Photobiol. 11 (1970) 457-\&.

[3] R.E. Blankenship, Molecular Mechanisms of Photosynthesis, Blackwell Science, Oxford, U.K, 2002

[4] W. Ruttinger, G.C. Dismukes, Chem. Rev. 97 (1997) 1-24

[5] J. Limburg, J.S. Vrettos, L.M. Liable-Sands, A.L. Rheingold, R.H. Crabtree, G.W. Brudvig, Science 283 (1999) 1524-1527.

[6] J. Limburg, J.S. Vrettos, H.Y. Chen, J.C. de Paula, R.H. Crabtree, G.W. Brudvig, J. Am. Chem. Soc. 123 (2001) 423-430.

[7] R. Manchanda, G.W. Brudvig, R.H. Crabtree, Coord. Chem. Rev. 144 (1995) 1-38.

[8] C.S. Mullins, V.L. Pecoraro, Coord. Chem. Rev. 252 (2008) 416-443.

[9] G.C. Dismukes, R. Brimblecombe, G.A.N. Felton, R.S. Pryadun, J.E. Sheats, L. Spiccia, G.F. Swiegers, Acc. Chem. Res. 42 (2009) 1935-1943.

[10] J.S. Kanady, E.Y. Tsui, M.W. Day, T. Agapie, Science 333 (2011) 733-736.

[11] C.R. Hamilton, R.A. Baglia, A.D. Gordon, M.J. Zdilla, J. Am. Chem. Soc. 133 (2011) 4208-4211.

[12] S. Mukherjee, J.A. Stull, J. Yano, T.C. Stamatatos, K. Pringouri, T.A. Stich, K.A. Abboud, R.D. Britt, V.K. Yachandra, G. Christou, Proc. Natl. Acad. Sci. U. S. A. 109 (2012) 2257-2262.

[13] S. Vaddypally, S.K. Kondaveeti, M.J. Zdilla, Inorg. Chem. 51 (2012) 3950-3952.

[14] E.Y. Tsui, T. Agapie, Proc. Natl. Acad. Sci. U. S. A. 110 (2013) 10084-10088.

[15] J.S. Kanady, P.-H. Lin, K.M. Carsch, R.J. Nielsen, M.K. Takase, W.A. Goddard, T. Agapie, J. Am. Chem. Soc. 136 (2014) 14373-14376.

[16] E.S. Koumousi, S. Mukherjee, C.M. Beavers, S.J. Teat, G. Christou, T.C. Stamatatos, Chem. Commun. 47 (2011) 11128-11130.

[17] M. Yagi, K.V. Wolf, P.J. Baesjou, S.L. Bernasek, G.C. Dismukes, Angew. Chem. Int. Ed. 40 (2001) 2925-2928.

[18] Y. Naruta, M. Sasayama, T. Sasaki, Angew. Chem. Int. Ed. 33 (1994) 1839-1841.

[19] S.W. Gersten, G.J. Samuels, T.J. Meyer, J. Am. Chem. Soc. 104 (1982) 4029-4030.

[20] W. Ruettinger, M. Yagi, K. Wolf, S. Bernasek, G.C. Dismukes, J. Am. Chem. Soc. 122 (2000) 10353-10357.

[21] Y. Shimazaki, T. Nagano, H. Takesue, B.H. Ye, F. Tani, Y. Naruta, Angew. Chem. Int. Ed. 43 (2004) 98-100

[22] M. Yagi, K. Narita, J. Am. Chem. Soc. 126 (2004) 8084-8085.

[23] A.K. Poulsen, A. Rompel, C.J. McKenzie, Angew. Chem. Int. Ed. 44 (2005) 6916-6920.

[24] R. Brimblecombe, A. Koo, G.C. Dismukes, G.F. Swiegers, L. Spiccia, J. Am. Chem. Soc. 132 (2010) 2892-2894.

[25] E.A. Karlsson, B.-L. Lee, T. Åkermark, E.V. Johnston, M.D. Kärkäs, J. Sun, Ö. Hansson, J.-E. Bäckvall, B. Åkermark, Angew. Chem. Int. Ed. 50 (2011) 11715-11718.

[26] C. Zhang, C. Chen, H. Dong, J.-R. Shen, H. Dau, J. Zhao, Science 348 (2015) 690-693.

[27] R.A. Binstead, C.W. Chronister, J.F. Ni, C.M. Hartshorn, T.J. Meyer, J. Am. Chem. Soc 122 (2000) 8464-8473.

[28] D. Geselowitz, T.J. Meyer, Inorg. Chem. 29 (1990) 3894-3896.

[29] M. Yagi, Y. Osawa, N. Sukegawa, M. Kaneko, Langmuir 15 (1999) 7406-7408.

[30] C. Sens, I. Romero, M. Rodriguez, A. Llobet, T. Parella, J. Benet-Buchholz, J. Am. Chem. Soc. 126 (2004) 7798-7799.
[31] K. Yamamoto, S. Nakazawa, T. Imaoka, Molecular crystals and liquid crystals science and technology section a, Mol. Cryst. Liq. Cryst. 379 (2002) 407-412.

[32] G.N. George, R.C. Prince, S.P. Cramer, Science 243 (1989) 789-791.

[33] J.A. Kirby, A.S. Robertson, J.P. Smith, A.C. Thompson, S.R. Cooper, M.P. Klein, J. Am. Chem. Soc. 103 (1981) 5529-5537.

[34] V.K. Yachandra, K. Sauer, M.P. Klein, Chem. Rev. 96 (1996) 2927-2950.

[35] J. Yano, Y. Pushkar, P. Glatzel, A. Lewis, K. Sauer, J. Messinger, U. Bergmann, V. Yachandra, J. Am. Chem. Soc. 127 (2005) 14974-14975.

[36] Y. Umena, K. Kawakami, J.-R. Shen, N. Kamiya, Nature 473 (2011) 55-60.

[37] M. Suga, F. Akita, K. Hirata, G. Ueno, H. Murakami, Y. Nakajima, T. Shimizu, K. Yamashita, M. Yamamoto, H. Ago, J.-R. Shen, Nature 517 (2015) 99-103.

[38] H. Dau, A. Grundmeier, P. Loja, M. Haumann, Philos. Trans. R. Soc. B 363 (2008) 1237-1243.

[39] K.M. Davis, Y.N. Pushkar, J. Phys. Chem. B 119 (2015) 3492-3498.

[40] J. Yano, J. Kern, K. Sauer, M.J. Latimer, Y. Pushkar, J. Biesiadka, B. Loll, W. Saenger, J. Messinger, A. Zouni, V.K. Yachandra, Science 314 (2006) 821-825.

[41] E.M. Sproviero, J.A. Gascon, J.P. McEvoy, G.W. Brudvig, V.S. Batista, J. Am. Chem. Soc. 130 (2008) 6728-6730.

[42] J. Yano, J. Kern, Y. Pushkar, K. Sauer, P. Glatzel, U. Bergmann, J. Messinger, A. Zouni, V.K. Yachandra, Philos. Trans. R. Soc. B 363 (2008) 1139-1147.

[43] E.M. Sproviero, J.A. Gascon, J.P. McEvoy, G.W. Brudvig, V.S. Batista, J. Inorg. Biochem. 100 (2006) 786-800.

[44] P.E.M. Siegbahn, M. Lundberg, Photochem. Photobiol. Sci. 4 (2005) 1035-1043.

[45] S. Zein, L.V. Kulik, J. Yano, J. Kern, Y. Pushkar, A. Zouni, V.K. Yachandra, W. Lubitz, F. Neese, J. Messinger, Philos. Trans. R. Soc. B 363 (2008) 1167-1177.

[46] E.M. Sproviero, J.A. Gascon, J.P. McEvoy, G. Brudvig, V.S. Batista, J. Am. Chem. Soc. 130 (2008) 3428-3442.

[47] J. Limburg, G.W. Brudvig, R.H. Crabtree, J. Am. Chem. Soc. 119 (1997) 2761-2762.

[48] H.Y. Chen, R. Tagore, G. Olack, J.S. Vrettos, T.C. Weng, J. Penner-Hahn, R.H. Crabtree, G.W. Brudvig, Inorg. Chem. 46 (2007) 34-43.

[49] H. Wolpher, P. Huang, M. Borgström, J. Bergquist, S. Styring, L. Sun, B. Åkermark, Catal. Today 98 (2004) 529-536.

[50] K.J. Young, B.J. Brennan, R. Tagore, G.W. Brudvig, Acc. Chem. Res. 48 (2015) 567-574.

[51] C. Baffert, S. Romain, A. Richardot, J.-C. Leprêtre, B. Lefebvre, A. Deronzier, M.-N. Collomb, J. Am. Chem. Soc. 127 (2005) 13694-13704.

[52] K. Narita, T. Kuwabara, K. Sone, K.-i. Shimizu, M. Yagi, J. Phys. Chem. B 110 (2006) 23107-23114.

[53] M. Yagi, M. Toda, S. Yamada, H. Yamazaki, Chem. Commun. 46 (2010) 8594-8596.

[54] M.M. Najafpour, A.N. Moghaddam, H. Dau, I. Zaharieva, J. Am. Chem. Soc. 136 (2014) 7245-7248.

[55] J. Limburg, V.A. Szalai, G.W. Brudvig, J. Chem. Soc. Dalton Trans. (1999) 1353-1361.

[56] Y. Gao, R.H. Crabtree, G.W. Brudvig, Inorg. Chem. 51 (2012) 4043-4050.

[57] C.W. Cady, K.E. Shinopoulos, R.H. Crabtree, G.W. Brudvig, Dalton Trans. 39 (2010) 3985-3989.

[58] M. Lundberg, M.R.A. Blomberg, P.E.M. Siegbahn, Theor. Chem. Accounts 110 (2003) 130-143.

[59] M. Lundberg, M.R.A. Blomberg, P.E.M. Siegbahn, Inorg. Chem. 43 (2004) 264-274.

[60] M. Hatakeyama, H. Nakata, M. Wakabayashi, S. Yokojima, S. Nakamura, J. Phys. Chem. A 116 (2012) 7089-7097.

[61] T. Zhou, X. Lin, X. Zheng, J. Chem. Theory Comput. 9 (2013) 1073-1080.

[62] I. Rivalta, K.R. Yang, G.W. Brudvig, V.S. Batista, ACS Catal. 5 (2015) 2384-2390.

[63] S. Khan, K.R. Yang, M.Z. Ertem, V.S. Batista, G.W. Brudvig, ACS Catal. 5 (2015) 7104-7113.

[64] D.M. Proserpio, R. Hoffmann, G.C. Dismukes, J. Am. Chem. Soc. 114 (1992) 4374-4382.

[65] G. Aullon, E. Ruiz, S. Alvarez, Chem. Eur. J. 8 (2002) 2508-2515.

[66] M. Lundberg, P.E.M. Siegbahn, Chem. Phys. Lett. 401 (2005) 347-351.

[67] E.M. Sproviero, G.W. Brudvig, V.S. Batista, 240th ACS National Meeting, Boston, MA, CATL-99, 2010

[68] L. Noodleman, J. Chem. Phys. 74 (1981) 5737-5743.

[69] L. Noodleman, E.R. Davidson, Chem. Phys. 109 (1986) 131-143.

[70] G. Vacek, J.K. Perry, J.M. Langlois, Chem. Phys. Lett. 310 (1999) 189-194.

[71] J. Tomasi, B. Mennucci, R. Cammi, Chem. Rev. 105 (2005) 2999-3093.

[72] C. Peng, H. Bernhard Schlegel, Isr. J. Chem. 33 (1993) 449-454.

[73] C. Peng, P.Y. Ayala, H.B. Schlegel, M.J. Frisch, J. Comput. Chem. 17 (1996) 49-56.

[74] D. Kumar, W. Thiel, S.P. de Visser, J. Am. Chem. Soc. 133 (2011) 3869-3882.

[75] A.D. Becke, J. Chem. Phys. 98 (1993) 5648-5652.

[76] C. Lee, W. Yang, R.G. Parr, Phys. Rev. B 37 (1988) 785-789.

[77] P.E.M. Siegbahn, Philos. Trans. R. Soc. B 363 (2008) 1221-1228.

[78] P.E.M. Siegbahn, F. Himo, J. Biol. Inorg. Chem. 14 (2009) 643-651.

[79] M. Busch, E. Ahlberg, I. Panas, Phys. Chem. Chem. Phys. 13 (2011) 15069-15076

[80] M.J. Frisch, G.W. Trucks, H.B. Schlegel, G.E. Scuseria, M.A. Robb, J.R. Cheeseman, G. Scalmani, V. Barone, B. Mennucci, G.A. Petersson, H. Nakatsuji, M. Caricato, X. Li, H.P. Hratchian, A.F. Izmaylov, J. Bloino, G. Zheng, J.L. Sonnenberg, M. Hada, M. Ehara, K. Toyota, R. Fukuda, J. Hasegawa, M. Ishida, T. Nakajima, Y. Honda, O. Kitao, H. Nakai, T. Vreven, J.A. Montgomery Jr., J.E. Peralta, F. Ogliaro, M.J. Bearpark, J. Heyd, E.N. Brothers, K.N. Kudin, V.N. Staroverov, R. Kobayashi, J. Normand, K. Raghavachari, A.P. Rendell, J.C. Burant, S.S. Iyengar, J. Tomasi, M. Cossi, N. Rega, N.J. Millam, M. Klene, J.E. Knox, J.B. Cross, V. Bakken, C. Adamo, J. Jaramillo, R. Gomperts, R.E. Stratmann, O. Yazyev, A.J. Austin, R. Cammi, C. Pomelli, J.W. Ochterski, R.L. Martin, K. Morokuma, V.G. Zakrzewski, G.A. Voth, P. Salvador, J.J. Dannenberg, S. Dapprich, A.D. Daniels, Ö. Farkas, J.B. Foresman, J.V. Ortiz, J. Cioslowski, D.J. Fox, Gaussian, Inc., Wallingford, CT, USA (2009).

[81] W. Humphrey, A. Dalke, K. Schulten, J. Mol. Graph. 14 (1996) 33-\&.

[82] J. Stone, Computer Science Department, University of Missouri-Rolla (1998).

[83] R.F. Ribeiro, A.V. Marenich, C.J. Cramer, D.G. Truhlar, J. Phys. Chem. B 115 (2011) 14556-14562. 
[84] J.H. Jensen, Phys. Chem. Chem. Phys. 17 (2015) 1463-9076.

[85] J. Ho, Phys. Chem. Chem. Phys. 17 (2015) 2859-2868.

[86] K.J. Laidler, J.H. Meiser, B.C. Sanctuary J. (2002) (Pages).

[87] A.V. Marenich, C.J. Cramer, D.G. Truhlar, J. Phys. Chem. B 113 (2009) 6378-6396.

[88] Z. Gross, H.B. Gray, Comments Inorg. Chem. 27 (2006) 61-72.

[89] M. Lundberg, P.E.M. Siegbahn, Phys. Chem. Chem. Phys. 6 (2004) 4772-4780.

[90] H. Isobe, M. Shoji, S. Yamanaka, Y. Umena, K. Kawakami, N. Kamiya, J.R. Shen, K. Yamaguchi, Dalton Trans. 41 (2012) 13727-13740.

[91] C. Kupitz, S. Basu, I. Grotjohann, R. Fromme, N.A. Zatsepin, K.N. Rendek, M.S. Hunter, R.L. Shoeman, T.A. White, D. Wang, D. James, J.-H. Yang, D.E. Cobb, B. Reeder, R.G. Sierra, H. Liu, A. Barty, A.L. Aquila, D. Deponte, R.A. Kirian, S. Bari, J.J. Bergkamp, K.R. Beyerlein, M.J. Bogan, C. Caleman, T.-C. Chao, C.E. Conrad, K.M. Davis, H. Fleckenstein, L. Galli, S.P. Hau-Riege, S. Kassemeyer, H. Laksmono, M. Liang, L. Lomb, S. Marchesini, A.V. Martin, M. Messerschmidt, D. Milathianaki, K. Nass, A. Ros, S. Roy-Chowdhury, K. Schmidt, M. Seibert, J. Steinbrener, F. Stellato, L. Yan, C. Yoon, T.A. Moore, A.L. Moore, Y. Pushkar, G.J. Williams, S. Boutet, R.B. Doak, U. Weierstall, M. Frank, H.N. Chapman, J.C.H. Spence, P. Fromme, Nature 513 (2014) 261-265.

[92] F. Neese, J. Phys. Chem. Solids 65 (2004) 781-785.

[93] D.A. Pantazis, V. Krewald, M. Orio, F. Neese, Dalton Trans. 39 (2010) 4959-4967.

[94] N. Lehnert, R.Y.N. Ho, L. Que, E.I. Solomon, J. Am. Chem. Soc. 123 (2001) 12802-12816.

[95] C.A. Reed, S.K. Cheung, Proc. Natl. Acad. Sci. U. S. A. 74 (1977) 1780-1784.

[96] N. Lehnert, F. Neese, R.Y.N. Ho, L. Que, E.I. Solomon, J. Am. Chem. Soc. 124 (2002) $10810-10822$.

[97] P.E.M. Siegbahn, Chem. Eur. J. 12 (2006) 9217-9227.

[98] P.E.M. Siegbhan, Inorg. Chem. 47 (2008) 1779-1786.

[99] P.E.M. Siegbahn, Inorg. Chem. 39 (2000) 2923-2925.

[100] H. Dau, L. Iuzzolino, J. Dittmer, Biochim. Biophys. Acta 1503 (2001) 24-39.
[101] J. Messinger, Phys. Chem. Chem. Phys. 6 (2004) 4764-4771.

[102] V.L. Pecoraro, M.J. Baldwin, M.T. Caudle, W.Y. Hsieh, N.A. Law, Pure Appl. Chem. 70 (1998) 925-929.

[103] V.A. Szalai, D.A. Stone, G. Brudvig, in: G. Garab (Ed.), Photosynthesis: Mechanisms and Effects, Dordrecht, The Netherlands 1998, pp. 1403-1406.

[104] J.S. Vrettos, J. Limburg, G.W. Brudvig, Biochim. Biophys. Acta 1503 (2001) 229-245

[105] R. Gupta, T. Taguchi, B. Lassalle-Kaiser, E.L. Bominaar, J. Yano, M.P. Hendrich, A.S. Borovik, Proc. Natl. Acad. Sci. U. S. A. 112 (2015) 5319-5324

[106] T. Taguchi, R. Gupta, B. Lassalle-Kaiser, D.W. Boyce, V.K. Yachandra, W.B. Tolman, J. Yano, M.P. Hendrich, A.S. Borovik, J. Am. Chem. Soc. 134 (2012) 1996-1999.

[107] R.D. Britt, D.L.M. Suess, T.A. Stich, Proc. Natl. Acad. Sci. U. S. A. 112 (2015) 5265-5266

[108] F. Rappaport, M. Blancharddesce, J. Lavergne, BBA-Bioenergetics 1184 (1994) 178-192.

[109] F. Rappaport, N. Ishida, M. Sugiura, A. Boussac, Energy Environ. Sci. 4 (2011) $2520-2524$

[110] M.R. Razeghifard, R.J. Pace, Biochemistry 38 (1999) 1252-1257.

[111] T. Noguchi, H. Suzuki, M. Tsuno, M. Sugiura, C. Kato, Biochemistry 51 (2012) 3205-3214.

[112] M. Haumann, P. Liebisch, C. Muller, M. Barra, M. Grabolle, H. Dau, Science 310 (2005) 1019-1021.

[113] J. Kern, R. Tran, R. Alonso-Mori, S. Koroidov, N. Echols, J. Hattne, M. Ibrahim, S. Gul, H. Laksmono, R.G. Sierra, R.J. Gildea, G. Han, J. Hellmich, B. Lassalle-Kaiser, R. Chatterjee, A.S. Brewster, C.A. Stan, C. Glöckner, A. Lampe, D. DiFiore, D. Milathianaki, A.R. Fry, M.M. Seibert, J.E. Koglin, E. Gallo, J. Uhlig, D. Sokaras, T.-C. Weng, P.H. Zwart, D.E. Skinner, M.J. Bogan, M. Messerschmidt, P. Glatzel, G.J. Williams, S. Boutet, P.D. Adams, A. Zouni, J. Messinger, N.K. Sauter, U. Bergmann, J. Yano, V.K. Yachandra, Nat. Commun. 5 (2014) 4371. 